\title{
Inflammatory Response in Patients under Coronary Artery Bypass Grafting Surgery and Clinical Implications: A Review of the Relevance of Dexmedetomidine Use
}

\author{
Neusa Maria Heinzmann Bulow, ${ }^{1}$ Elisângela Colpo, ${ }^{1}$ Marta Frescura Duarte, ${ }^{1}$ \\ Eduardo Francisco Mafassioly Correa, ${ }^{1}$ Rochelle Silveira Schlosser, ${ }^{1}$ Anelise Lauda, ${ }^{1}$ \\ Ige Joseph Kade, ${ }^{2}$ and João Batista Teixeira Rocha ${ }^{1}$ \\ ${ }^{1}$ Departamento de Bioquimica e Biologia Molecular, Programa de Pos-Graduação em Ciências Biológicas: Bioquímica Toxicológica, \\ Centro de Ciências Naturais e Exatas, Universidade Federal de Santa Maria, 97105-900 Santa Maria, RS, Brazil \\ ${ }^{2}$ Department of Biochemistry, School of Sciences, Federal University of Technology of Akure, Ondo State, Nigeria
}

Correspondence should be addressed to João Batista Teixeira Rocha; jbtrocha@yahoo.com.br

Received 10 September 2013; Accepted 9 October 2013; Published 27 April 2014

Academic Editors: S. D. Bergese, F. Cavaliere, S. Cho, and D. Ma

Copyright (C) 2014 Neusa Maria Heinzmann Bulow et al. This is an open access article distributed under the Creative Commons Attribution License, which permits unrestricted use, distribution, and reproduction in any medium, provided the original work is properly cited.

\begin{abstract}
Despite the fact that coronary artery bypass grafting surgery (CABG) with cardiopulmonary bypass (CPB) prolongs life and reduces symptoms in patients with severe coronary artery diseases, these benefits are accompanied by increased risks. Morbidity associated with cardiopulmonary bypass can be attributed to the generalized inflammatory response induced by blood-xenosurfaces interactions during extracorporeal circulation and the ischemia/reperfusion implications, including exacerbated inflammatory response resembling the systemic inflammatory response syndrome (SIRS). The use of specific anesthetic agents with antiinflammatory activity can modulate the deleterious inflammatory response. Consequently, anti-inflammatory anesthetics may accelerate postoperative recovery and better outcomes than classical anesthetics. It is known that the stress response to surgery can be attenuated by sympatholytic effects caused by activation of central ( $\alpha$ - $) 2$-adrenergic receptor, leading to reductions in blood pressure and heart rate, and more recently, that they can have anti-inflammatory properties. This paper discusses the clinical significance of the dexmedetomidine use, a selective $(\alpha$-)2-adrenergic agonist, as a coadjuvant in general anesthesia. Actually, dexmedetomidine use is not in anesthetic routine, but this drug can be considered a particularly promising agent in perioperative multiple organ protection.
\end{abstract}

\section{Introduction}

1.1. Inflammatory Response and Ischemia/Reperfusion in $C A B G$ Surgery. Surgery induces a variety of metabolic, endocrine, and immune changes known as the "stress response," which may lead to prolonged in-hospital stay. The clinical manifestation of this reaction includes postoperative complications such as respiratory failure, wound infections [1], myocardial damage with contractile dysfunction, renal impairment, coagulopathy, neurologic dysfunction [2], and altered liver function with an increased mortality [3].

Inflammatory response in cardiac surgical patients is produced by complex interactions with numerous pathways including generation or activation of complement, cytokines, neutrophils, thrombin, mast cells, and other multiple inflammatory mediators. Cardiopulmonary bypass responses have often been compared with the pathophysiologic changes occurring in systemic inflammatory response syndrome (SIRS) [4] and remain not fully understood. Several interlinked mechanisms could play a role in the pathological effects associated with cardiopulmonary bypass, for instance, the exposure of blood to nonphysiologic surfaces, surgical trauma, anesthesia, changes in body temperature, increased intestinal permeability to endotoxins, and ischemia/reperfusion injury [5]. It results in a complex immunologic reaction with the release into circulation of 


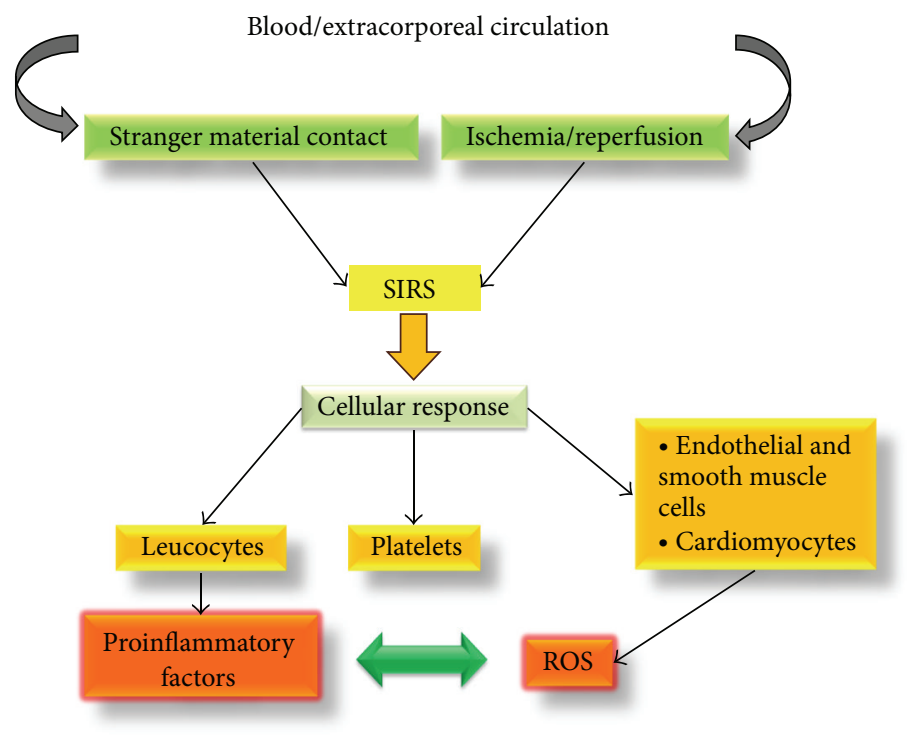

Scheme 1: Cardiopulmonary bypass and the extracorporeal circulation responses with the pathophysiologic changes resembling the systemic inflammatory response syndrome (SIRS). The contact of blood with xenosurfaces of the extracorporeal machine device, the ischemia/reperfusion, and the hyperbaric oxygen triggered SIRS-like pathophysiological responses. The SIRS-like response is associated with overactivation of leukocytes, platelets (which can contribute to an increased coagulopathy), and endothelial and cardiac cell. The secretion of proinflammatory factors by leucocytes and the increase tension and blood oxygenation stimulate the overproduction of reactive oxygen species (ROS), which feeds a vicious cycle of inflammation $\Longleftrightarrow$ ROS production.

arachidonic acid metabolites, proinflammatory cytokines, endothelins, platelet-activating factors, endothelial, and leukocyte adhesion molecules that stimulate the overproduction of reactive oxygen species $[6,7]$ (Scheme 1).

Although it has been shown that, compared with clinical management alone, conventional coronary artery bypass grafting surgery with cardiopulmonary bypass prolongs life and reduces symptoms in patients with severe coronary artery diseases, these benefits are accompanied by increased risks of transfusions (30-90\%), mortality (2-6\%), stroke $(2 \%)$, atrial fibrillation (30\%), and neurocognitive dysfunction $(50-60 \%)[8,9]$. The adverse clinical consequences, associated with conventional coronary artery bypass surgery, have been largely attributed to the extracorporeal blood circulation (ECC) on cardiopulmonary bypass circuit, general systemic effects (including exacerbated inflammatory response resembling the SIRS, Scheme 1), hypothermic cardiac arrest, aortic cannulation, and cross-clamping [10-12]. Consequently, it may be of interest to study the potential benefit of specific anesthetic drugs exhibiting anti-inflammatory mechanism. By modulating inflammatory response, anesthetic drugs could reduce the postoperative complications and mortality associated with CABG.

One potential candidate that has been little explored is dexmedetomidine. Dexmedetomidine, an $(\alpha)$-2-adrenergic receptor agonist, can provide anxiolysis and sedation without respiratory depression [13]. It decreases central nervous system sympathetic outflow in a dose-dependent manner and has analgesic effects described as opioid-sparing effect. There is increasing evidence that dexmedetomidine has organ protective effects against ischemic and hypoxic injury, including cardioprotection, neuroprotection, and renoprotection [13]. However, little is known about the cellular and molecular mechanism(s) involved in dexmedetomidine protective effects. Here we will discuss the potential systemic antioxidant and anti-inflammatory action of dexmedetomidine and its possible relationship with cardio- and neuroprotective effects after coronary artery bypass grafting surgery (CABG).

\section{Cardiopulmonary Bypass (CPB)}

Cardiopulmonary bypass $(\mathrm{CPB})$ replaces the functions of the heart and lungs during cardiac surgery, allowing the heart to be opened and operated on (Figure 1). The first successful human intracardiac operation was performed by Gibbon Jr in 1953, using a mechanical extracorporeal pump oxygenator [14]. Despite the long time since the first CPB surgery and numerous studies about CPB pathophysiological side effects, the complex mechanisms involved in the responses of blood and tissues to cardiopulmonary bypass are still far from clear.

Clinical points of evidence suggest that morbidity associated with cardiopulmonary bypass can in part be attributed to the generalized inflammatory response induced by bloodxenosurfaces (from catheters and filtration membranes) interactions during extracorporeal circulation [4] (Scheme 1, Figure 1). Although conflicting data exist, the prominent hypothesis is that a metabolic unbalance occurs during extracorporeal blood recirculation involving every line of the inflammatory response including complement activation. 
Standard extracorporeal perfusion system

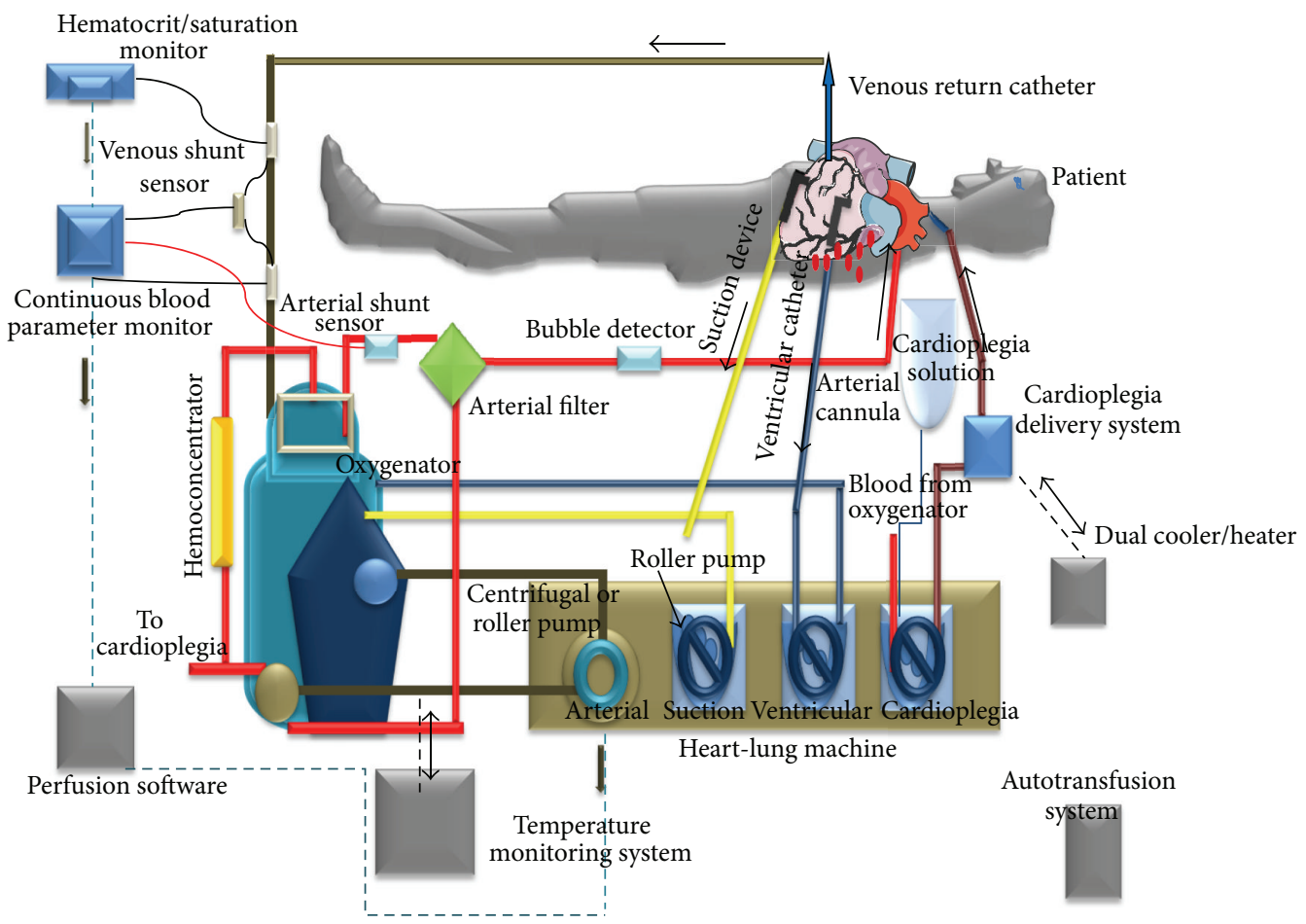

(a)



(b)

Figure 1: Overview of a standard extracorporeal circulation system (upper panel) and a detailed view of a heart undergoing artery bypass grafting surgery (lower panel). Cardiopulmonary bypass is achieved by gravity drainage of blood from the vena cava into a reservoir, followed by its pumping through a heat exchanger, oxygenator, and filter, followed by its return to the arterial system, usually the ascending aorta, by means of a centrifugal or roller pump. The heart is excluded from the patient's circulation by a single venous cannula inserted into the right atrium and advanced into the inferior vena cava, or by dual catheters placed into the superior and inferior vena cava. An aortic crossclamp is placed between the anterograde cardioplegia catheter and the arterial inflow catheter to separate the heart from the circulation and allow cardioplegic arrest. When the heart is isolated from the circulation, total cardiopulmonary bypass is present, and ventilation of the lungs is no longer necessary to maintain oxygenation. The bypass pump produces nonpulsatile flow into the patient's aorta by either a centrifugal or roller pump. Myocardial preservation is achieved by decreasing myocardial oxygen consumption by infusing cardioplegia solutions containing potassium into the aortic root, which in the presence of a distally cross-clamped aorta and competent aortic valve ensures diversion of the solution into the coronary arteries. Alternatively, the cardioplegia solution may be administered in retrograde fashion through a cannula placed into the coronary sinus. An additional route for infusion of cardioplegia solutions is directly into newly placed bypass grafts. Cardioplegia solutions may also contain many additives, including blood, insulin, glucose, aspartate, glutamate, calcium, magnesium, nitroglycerine, and superoxide dismutase. None of these additives are definitively better than cold blood cardioplegia with a short cross-clamp time. 


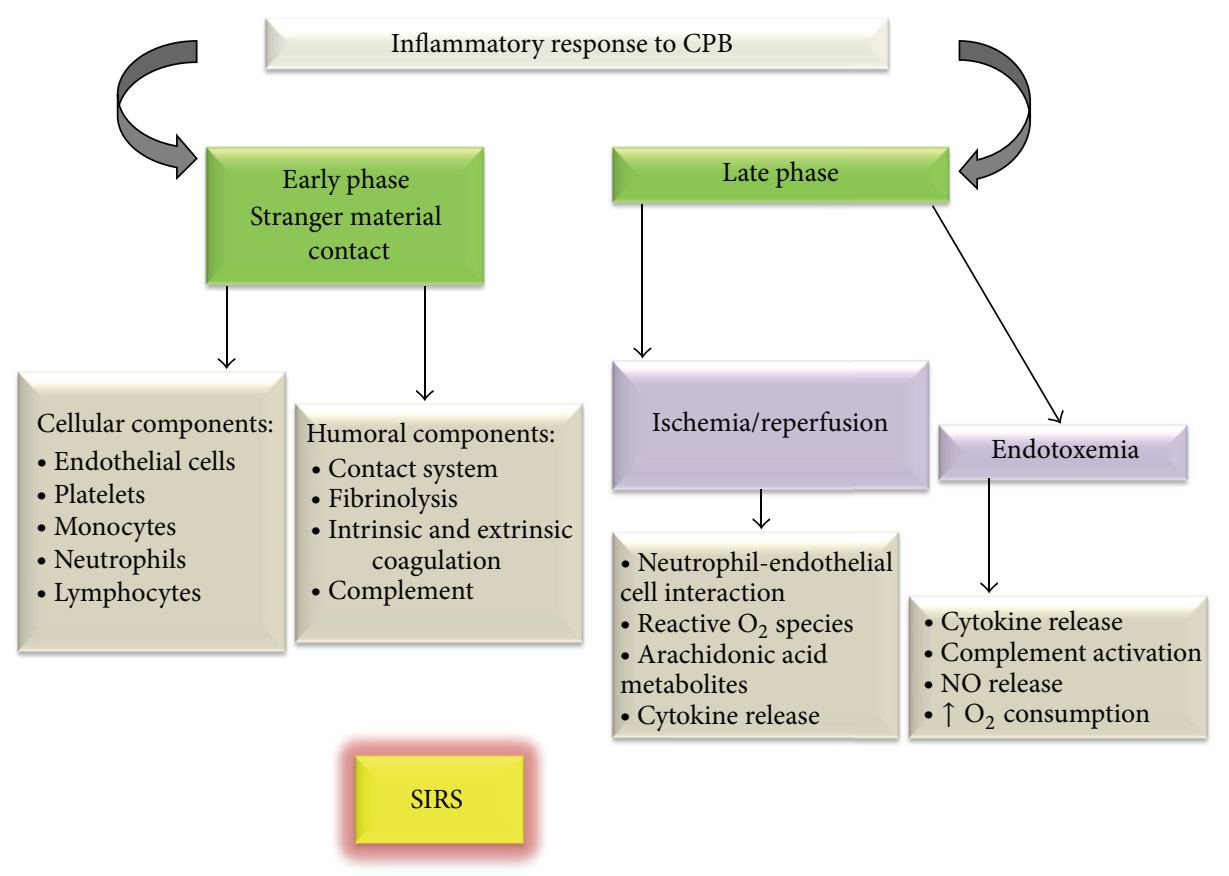

Scheme 2: The inflammatory response to cardiopulmonary bypass is divided into 2 phases: "early" and "late" phases. The first phase is induced by the contact with xenosurfaces and the late phase is more related to oxygen reperfusion after ischemia and endotoxemia.

Total perioperative values of inflammatory markers are probably less important than the balance between the oxidative inflammatory cascade and anti-inflammatory feedback mechanisms. Oxidative stress and inflammation are related and perhaps inseparable and a reduced cytokine response may be directly translated into changes in clinical outcomes $[15,16]$.

The pump and the oxygenator are used for cardiopulmonary bypass function in a nonphysiologic manner, with altered vascular pressure and gas composition. Inflammation is the initial, nonspecific response of vascularized tissue to a variety of injuries, involving both the activation of humoral and cellular inflammatory pathways. Significant hemodilution also occurs leading to a dilution and denaturation of plasma proteins. The blood exposition to nonendothelial surfaces activates the production of vasoactive mediators, altering capillary permeability and causing hemolysis (which increase the free concentration of the prooxidant heme and nonheme iron) and the coagulation system will be impaired [17]. One important question that needs to be explored in details is whether or not the ECC induced hemolysis increases the concentration of iron in pathologically relevant tissues such as brain, heart, and kidney. Increase in free hemoglobin, heme, and iron can further feed the pro-oxidative-proinflammatory cycle in different tissues [18-24]. The potential role of iron on "early and late phases" of inflammation associated with cardiopulmonary bypass (see below) should be investigated in detail as well as the possibility of utilizing chelation therapy as coadjuvant in patients at risk of developing SIRS-like response. Of particular significant, literature data have indicated a beneficial effect of deferoxamine in sepsis [25-27], which indicate that buffering of free iron can reduce the toxicity found in SIRS or SIRS-like situations [25-27].

The inflammatory response to cardiopulmonary bypass can be divided into 2 phases: "early" and "late" (Scheme 2). The early phase occurs as a result of the direct blood contact with nonendothelial surfaces, and the late phase is triggered by ischemia/reperfusion injury and endotoxemia (for a comprehensive review see the work of Warren and colleagues) [17].

In the early phase, coagulation becomes favorable, and it can be reduced or ameliorated with the administration of heparin before cardiopulmonary bypass initiation. When heparinized blood comes into cardiopulmonary bypass circuit, plasma proteins are adsorbed onto the circuit, leading to the activation of plasma protein systems and cell groups. These initiate a whole-body inflammatory response, associated with tissue edema, coagulopathy, and organ dysfunction [28]. With the course of cardiopulmonary bypass, the activation of the humoral and cellular components diminishes, but a second phase of inflammatory response initiates, which is related to ischemia/reperfusion injury and release of endotoxins from intestinal microflora [29]. The ischemia/reperfusion injury is mediated by neutrophilendothelial interactions (Figure 2). High levels of endothelial injury occur during ischemic period, resulting in neutrophil activation and sequestration on reperfusion. Independent of leukocytes, production of toxic reactive oxygen species also occurs, leading to release of arachidonic acid metabolites, proinflammatory cytokines by ischemic cells (e.g., plasma tumor necrosis factor-alpha and interleukins like IL-1, IL-6, and IL-8), and activation of the humoral protein systems [30]. The reintroduction of oxygen during reperfusion promotes 


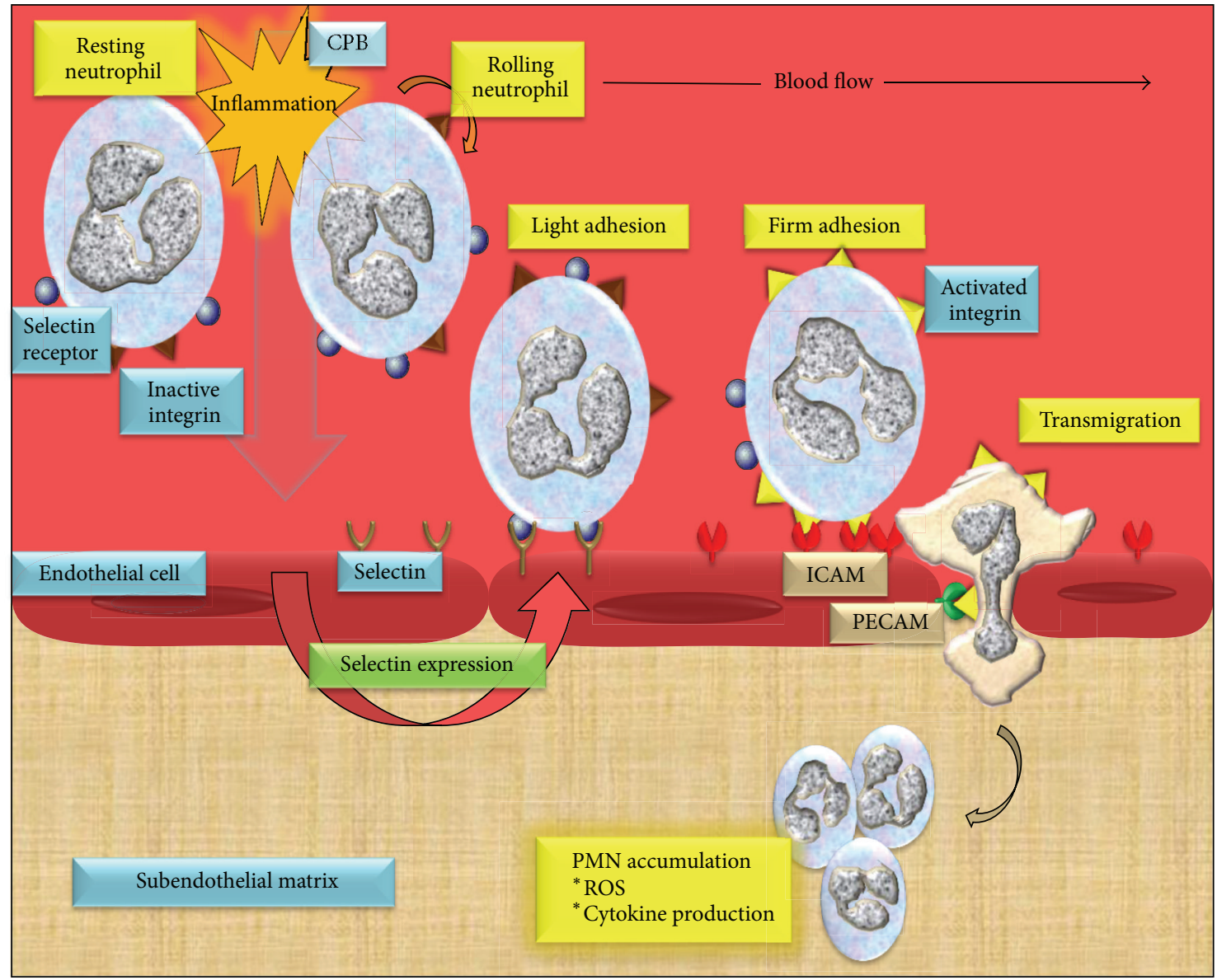

FIGURE 2: Cardiopulmonary bypass neutrophil activation. At neutrophil activation by inflammatory mediators a neutrophil rolling phase occurs, with posterior endothelial adhesivity, initially light, then firmly, resulting in the neutrophil-endothelial transmigration. It leads to neutrophil accumulation, reactive oxygen species (ROS) production, and cytokine release, maintaining the vicious circles. CPB: cardiopulmonary bypass; PMN: polymorphonuclears; ROS: reactive oxygen species; ICAM: intercellular adhesion molecule; PECAM: platelet/endothelial cell adhesion molecule.

a high concentration of damaging reactive oxygen species in previously ischemic cells and can damage cell membranes, denature proteins, and act as second messengers to stimulate an acute inflammatory response [4] (Schemes 2 and 3).

There are many possible sources of endotoxin, including lipopolysaccharides from cell wall of gram-negative bacteria, release during bypass, with gut translocation as the primary source [31]. The increased level of endotoxin related to cardiopulmonary bypass stimulates the release of nitric oxide and proinflammatory cytokines and increases levels of oxygen consumption [32]. These stimuli and the complexity of this disequilibrium, the balance between the processes of activation and inhibition of these systems, suggest that the implementation of effective anti-inflammatory and antioxidant strategies (though to be desirable in theory) can be a difficult challenge. Of particular pharmacological significance, recent experimental data have indicated that dexmedetomidine can attenuate sepsis-induced lung and kidney damage, in part by decreasing tissue migration of inflammatory cells in rats [33]. These results may indicate a potential role of dexmedetomidine as a negative modulator of SIRS-like response in cardiopulmonary bypass.

2.1. Miniextracorporeal Circulation (MECC). Biocompatible circuits designed to prevent the early activation of inflammatory cascades have been shown to affect some aspects of blood activation but not all. There have been some progresses in cardiopulmonary bypass design that has shown promising clinical outcomes, particularly those aiming to reduce the incidence of SIRS-like response and its complications. Recently, a new cardiopulmonary bypass system, the miniextracorporeal circulation (MECC), has been developed and its use has been associated with a reduced inflammatory response, when compared with the conventional system (standard cardiopulmonary bypass or extracorporeal circulation). It has no venous reservoir, a reduced priming volume, and less blood-synthetic interface contact (Figure 3).

In a review, Vohra and colleagues have consolidated the current literature on the mini-extracorporeal circulation system [34]. They have paid particular attention to 




Scheme 3: Complex cascade of pathophysiologic phenomena associated with ischemia/reperfusion in CABG. Anaerobic metabolism causes an increase on lactate and reduced $\mathrm{pH}$ with transmembrane pump impairment, which lead to an intracellular $\mathrm{Ca}^{2+}$ and $\mathrm{Na}^{+}$increases, and consequently cellular edema. Increase on intracellular $\mathrm{Ca}^{2+}$ activated phospholipase $\mathrm{A} 2$ and calpain, with arachidonic acid degranulate and protein synthesis inhibition. Thus, caspase and neutrophil activation occur with cellular apoptosis. The neutrophils activation induces membrane lesions and more proinflammatory mediators liberation, including nitric oxide, via nitric oxide synthase (NOS) activation and that leads to microvascular damage and endothelial impairment, in a vicious circle.

the role that cardiopulmonary bypass has in generating a systemic inflammatory response and have outlined ways in which MECC may be superior to standard cardiopulmonary bypass. The MECC system has shown promising results with regard to cardiac damage and end-organ dysfunction. Many studies cited by this author have also shown that changes in blood markers of inflammation (for instance, C-reactive protein, leucocytes, and cytokines) were lower when MECC is used. Of clinical significance, utilization of MECC has been associated with a decrease in complications found more frequently in standard ECC, particularly arrhythmias and thromboembolic events.

2.2. Oxidative Stress and Inflammation Associated with Coronary Artery Bypass Grafting Surgery (CABG). Reactive oxygen species are recognized as critical mediators of cardiac and neurologic injury during ischemia and reperfusion. Sources of these reactive oxygen species are the mitochondrial electron transport chain, the enzymes xanthine oxidase, NADPH oxidase, lipoxygenase/cyclooxygenase and nitric oxide synthase (NOS), and autooxidation of various substances, such as catecholamines. An unpaired electron usually makes the species highly reactive. There are endogenous antioxidant systems that counteract the potential for injury to cellular structures by regulating the balance of reactive oxygen species. These endogenous antioxidants are upregulated when exposure of the cell to the reactive oxygen species is increased. Under pathologic conditions, such as ischemia/reperfusion, their formation can rapidly overcome antioxidant defenses and cellular injury ensues. It is known that the cardiopulmonary bypass can be responsible for activating neutrophils that represents a prominent source of systemic primary reactive oxygen species production (Figure 2). The synergism of damages related to reactive oxygen species, activation, and infiltration of neutrophils in reperfused tissues has been well recognized for many years [4].

Some investigators suggested that strategies of neurological and myocardial protection must not be limited to interventions targeted at the heart or brain itself but should take into account the systemic response of organism to cardiopulmonary bypass $[35,36]$. These concepts should be 

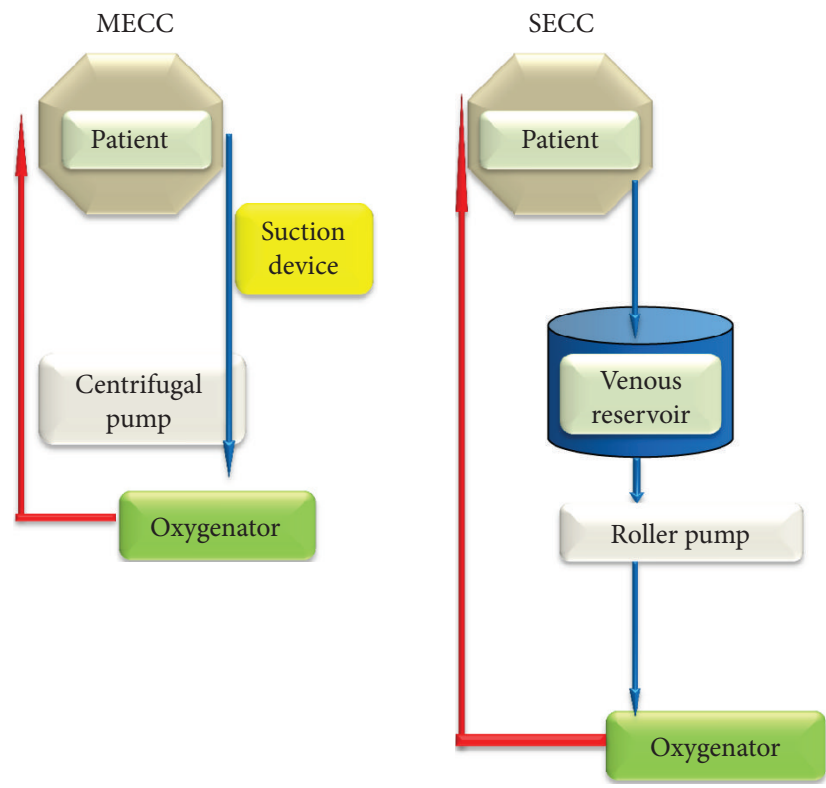

(1) Centrifugal pump
(2) Closed system
(3) Tubing length $<1 \mathrm{~m}$
(4) Priming volume $450 \mathrm{~mL}$

(1) Roller pump

(2) Open system: venous reservoir

(3) Tubing length $>2 \mathrm{~m}$

(4) Priming volume $1700 \mathrm{~mL}$

FIGURE 3: Miniextracorporeal circulation system compared to standard extracorporeal circulation system. In MECC system there exist various advantageous, such as a shorter tubular circuit, only a centrifugal pump use, a closed system where blood did not contact with air, and a smaller priming volume resulting in lesser hemodilution as compared to SECC. MECC: miniextracorporeal circulation; SECC: standard extracorporeal circulation.

particularly relevant for high-risk patients, who are more prone to organ injuries. But despite the improvement in the medical cardiac treatment, for instance, endovascular interventions and robotic surgery, cardiopulmonary bypass remains an essential part of many cardiovascular procedures. The multifactorial nature of inflammatory response suggests that no single pharmaceutical or technical intervention can in isolation inhibit the adverse clinical outcomes of such type of surgery. And more, theoretical and experimental data supporting that negative modulation of systemic inflammatory response (observed during and after cardiopulmonary bypass) might ameliorate brain injury found after cardiac surgery are not clear. Accordingly, the association between cardiopulmonary bypass-induced inflammation and neurocognitive deficits is still a matter of controversy.

Clermont et al. [37] demonstrated with electron spin resonance spectroscopy measurements the time course and origin of reactive oxygen species release, derived from myocardial source or not, in patients undergoing coronary artery surgery involving cardiopulmonary bypass. Their results demonstrated that systemic oxidative stress occurs in patients undergoing open heart surgery, illustrated by the increased alkyl and alkoxy radicals detected and quantified by electron spin resonance spectroscopy. Other studies have already taken an interest in classical indirect oxidative stress markers such as vitamins, antioxidant plasma status, or thiobarbituric acid reactive substances and the results were controversial. The concept that oxidative stress could influence postoperative outcome in patients subjected to coronary artery bypass surgery also remains a controversial and inconclusive issue [38-40].

Oxidative stress (measured by lipid peroxidation) also has been compared in patients undergoing coronary artery surgery with or without cardiopulmonary bypass (on-pump or off-pump) [41], and it has been shown to be lesser in the off-pump (without cardiopulmonary bypass) than in the onpump (with cardiopulmonary bypass) group. These results are not surprising since it is clear that the ischemia and reperfusion involved in on-pump surgery are expected to induce oxidative stress. However, there are some results in the literature indicating that glutathione levels decreased and catalase activity increased to similar values between on-pump or off-pump groups with a little difference between them [41]. These observations may support the assumptions of Milei and colleagues [42], that the induction of oxidative stress could be relatively benign. It is interesting to note that the patients in this study were at low risk with good ventricular function; it is expected, therefore, that these patients could have minimal increases in oxidative stress. The study of Milei and colleagues [42] investigated markers of oxidative stress in a small number of low risk patients (24 in total) undergoing coronary artery bypass surgery. They measure myocardial release of glutathione, myocardial antioxidants (vitamin E and ubiquinol), and lipid peroxidation markers 
(TBARS) in blood, as well as ultrastructural assessment of tissue injury (from myocardial biopsies) and evaluation of postischemic hemodynamic function and clinical outcome. The results show that there was evidence of increased glutathione release in the initial $20 \mathrm{~min}$ of reperfusion, and a decrease in tissue antioxidant levels of ubiquinol (but not vitamin $\mathrm{E}$ ), and minimal increase in tissue lipid peroxidation or any ultrastructural damage. The study indicates that, for the majority of low risk patients undergoing coronary artery bypass surgery, oxidative stress remains a constant underlying factor, unlikely to significantly influence clinical outcome as long as myocardial protection is provided and the ischemic duration is kept as short as possible. However, in critically ill patients an intervention to attenuate oxidative stress might be considered beneficial, because reactive oxygen species may contribute to myocardial stunning, infarction and apoptosis, and vascular disfunction [1-3].

\subsection{Neuroinflammation Associated with Coronary Artery} Bypass Grafting Surgery (CABG). It is largely suggested that neurocognitive decline after cardiopulmonary bypass results from an inflammatory response that is initiated by extracorporeal circulation [43-45]. However, a more comprehensive review of the literature does not consistently support this hypothesis. For example, in an animal model that included both elderly rats and diabetic rats, de Lange and colleagues [46] found no differences in short-term neurocognitive performance (8-14 days after surgery) in rats undergoing surgery with cardiopulmonary bypass, compared with those undergoing a sham operation. They noted an increase in cytokine release (interleukin-6) after cardiopulmonary bypass in diabetic rats but not in elderly rats. In humans, Westaby and colleagues [47] did not found an association between maximal levels of inflammatory markers (complement C4a and C5b-9) with early or late neurocognitive function after coronary artery bypass graft surgery with cardiopulmonary bypass. Furthermore, Parolari and colleagues [48] demonstrated that postoperative levels of inflammatory markers, including interleukin-6, plasma tumor necrosis factor-alpha, C-reactive protein, and fibrinogen, differed little in patients undergoing coronary artery bypass graft surgery with or without cardiopulmonary bypass.

Nevertheless, it is largely known that necrosis and apoptosis after an acute ischemic event are accompanied by other processes which lead to a posterior neurodegeneration. It was demonstrated that release of cytokines, such as tumor necrosis factor-alpha and interleukins, as mediated by oxidative stress and prolonged microglial activation by interleukin-1 induce to a neuronal degeneration that follow cerebral ischemia [49] and that excessive formation of reactive oxygen species induce to direct tissue damage and stimulate inflammatory and proapoptotic cascades [50]. Central norepinephrine release during brain ischemia also increases neuronal metabolism and carries to the formation of reactive oxygen species from autooxidation of neurotransmitters, induces damage caused by glutamate during ischemia, and can exacerbate the underlying disease of patients [49].
If the inflammatory response is or not the primary cause of neurocognitive injury after cardiopulmonary bypass, the question is whether or not neurocognitive decline in adult cardiac surgical patients could be related to the cardiopulmonary bypass pump. van Harten and colleagues [51] discuss the evidence for cardiopulmonary bypass-related neuronal injuries in adult cardiac surgery patients and review the evidence that immune priming is a key factor in the pathogenesis of cognitive dysfunction after cardiac surgery. They suggest further studies about pathophysiology of postoperative cognitive dysfunction (POCD) that may lead to strategies and therapies to prevent or attenuate POCD and also define the better choice of hypnotic and dose of opioid, on the inflammatory response to surgery and on the incidence of POCD. These studies could determine the benefit, if any, of immune system modulation, by anti-inflammatory agents and also by other drugs that may exert beneficial effects on the balance between pro- and anti-inflammatory mediators, such as interleukin-6 or tumor necrosis factor-alpha and interleukin-10, respectively.

A comparison of coronary artery bypass graft surgery with percutaneous coronary intervention failed to show difference in cognitive decline in patients undergoing cardiac revascularization [52]. Age is considered to be the strongest predictive factor of postoperative cognitive dysfunction (POCD) and coronary artery bypass grafting without the use of cardiopulmonary bypass could be considered less harmful to the patient group, especially in terms of neurological complications. Although an increasing number of patients with advanced age and other risk factors for neurocognitive injuries have been referred for coronary artery bypass grafting, Jensen and colleagues [53], in a randomized trial, investigated the effect of avoiding the heart-lung machine on cognitive function 1 year after surgery in aged patient population. They did not detect differences in cognitive outcomes in elderly high-risk patients 1 year after the operation between subjects which underwent coronary artery bypass grafting surgery without cardiopulmonary bypass with those subjected to extracorporeal circulation. The study of Jensen and colleagues [53] are in line with other randomized study about late cognitive outcome in younger patients with less advanced coronary artery disease and lower preoperative risk [54]. In Jensen et al. study [53], postoperative cognitive dysfunction, unexpectedly, tended to be less common in the on-pump group. This could be further suggestive that many other factors such as inflammatory processes including sternotomy, heparin administration, and hemodynamic variations may be responsible for cognitive dysfunction observed after surgery [55]. It seems that patient characteristics, such as the presence of atherosclerosis, are more relevant than the type of intervention as predictive factor of neurocognitive injury in patients with severe coronary artery disease [56]. In addition, late cognitive decline occurring 5 to 6 years after coronary artery bypass graft surgery did not differ in degree from longitudinal cognitive decline observed in patients of similar age either with coronary artery disease [57] or without coronary artery disease $[46,58]$. Perhaps, decline in neuropsychological tests with time is related to progression of underlying cardiovascular disease or simply to natural aging 
[59-61]. In fact, neurocognitive impairment in many patients undergoing cardiac surgery may be preexisting, although subclinical [62].

\subsection{S-100B as a Marker and Modulator of Neuroinflammation.} S100B protein is normally used as a marker of brain injury and can participate in the brain inflammatory response. At the nanomolar concentrations found in the brain extracellular space, under normal conditions, S100B acts as neurotrophic factor, promoting neuronal survival under stress conditions and neurite outgrowth [63] and stimulating the uptake of the cytotoxic glutamate by astrocytes [64]. The level of S100B in blood is considered a clinical marker of brain cell damage and/or increased permeability of the blood-brain barrier. Moreover, S100B release by astrocytes can be augmented upon stimulation by the proinflammatory cytokines tumor necrosis factor-alpha, interleukin-1 (IL-1), and interleukin6 (IL-6) [65-68]. As demonstrated before, cytokines contribute to a cascade of events typical of inflammation and especially proinflammatory cytokines, such as IL-6 and IL8 , are thought to contribute to the development of sickness behavior [69]. Trophic effects of the S100B protein on neurons depend on interaction with the receptor for advanced glycation end products (RAGE) [70], a multiligand receptor belonging to the immunoglobulin family that has been implicated in both neuroprotection and neurodegeneration, and in the inflammatory response [71]. Acute stimulation of RAGE with high doses of S100B causes neuronal apoptosis via overproduction of reactive oxygen species [72] and stimulates inducible nitric oxide synthase in astrocytes and microglia [73-75], which might contribute to astrocytic and neuronal apoptosis [75]. Moreover, S100B also stimulates interleukin-1 (IL-1) release from microglia [76].

S100B protein increases 50- to 100 -fold after cardiac surgery using standard cardiopulmonary bypass [77, 78], a finding that could support association between cardiopulmonary bypass and brain damage. The postoperative serum concentration of S-100B appears to increase with the duration of cardiopulmonary bypass and with the number of cerebral emboli detected by transcranial doppler imaging [79]. Several studies have suggested that, in the absence of clear neurologic signs, transient elevations in serum S100B protein can reflect subclinical cerebral damage $[80,81]$. But early release of S100B after cardiopulmonary bypass has not been associated with adverse neurological outcome. In contrast, cerebral complications such confusion, delayed awakening, and stroke have been correlated with late increase in S100B detected 5 to 48 hours after cardiopulmonary bypass [82]. The increase in plasma S100B could also be linked with postoperative delirium incidence [83] and be a consequence of S100B release by astrocytes stimulated by circulating proinflammatory mediators (IL-6, IL-8, etc.) [83, 84]. Such complex and not fully well characterized relationship between S100B, inflammatory markers, and neurobehavioral changes has been studied in more detail in elderly hip fracture patients [83].

Of particular clinical significance, many studies have demonstrated that the development of delirium in critically ill



Clonidine

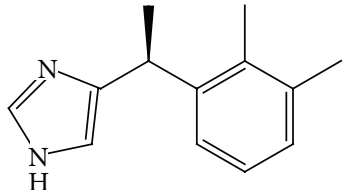

Dexmedetomidine
FIGURE 4: Dexmedetomidine and clonidine structural formulae.

patients increases morbidity, mortality, and healthcare costs $[85,86]$. Also a higher frequency of dementia in patients who presented with delirium at the end of the surgery has been hypothesized [87]. The neurocognitive impairments might reflect an irreversible brain damage triggered by surgery pathophysiological effects. Consequently, it could be supposed that the higher the level of S100B in a delirious patient, the higher the risk of dementia after delirium, and thus cerebral damage. This cerebral damage could be mediated via neuroinflammatory mechanisms because the level of S100B and the incidence of neurodegeneration are higher in patients with an infectious disease (which normally is associated with inflammatory response) as compared to noninfected subjects $[88,89]$.

\section{Alpha ( $\alpha$-)2-Adrenergic Receptor Agonists}

Alpha ( $\alpha$-)2-adrenergic receptor agonists have been utilized in surgery because they have sedative, analgesic, hemodynamic-stabilizing properties and sympatholytic pharmacologic effects [90, 91] (Figure 4).

The stress response to surgery can be attenuated by sympatholytic effects caused by postsynaptic activation of central $(\alpha-) 2$-adrenergic receptor, leading to reductions in blood pressure and heart rate [89]. Of clinical significance, two adrenergic agonists have been used as coadjuvant in general anesthesia or even as anesthetic agents by themselves, that is, clonidine and dexmedetomidine (Figure 5). Here we will briefly discuss the use of clonidine, because clonidine has a smaller selectivity for $(\alpha$-)2-adrenergic receptor than dexmedetomidine, consequently, a low efficacy as an anesthetic agent.

3.1. Clonidine. Clonidine was first used for postoperative pain relief and regional anesthesia [92-94]. In effect, clonidine has antinociceptive properties and reduces anesthetic requirements by attenuating sympathoadrenal responses during surgery and plasma concentrations of norepinephrine by stimulating presynaptic $(\alpha$-)2-adrenergic receptors. While the use of clonidine during coronary artery bypass graft surgery did not appear to influence the perioperative stress response [95], its immunomodulatory effects remain to be characterized. Of clinical significance, perioperative use of clonidine was associated with reduction in the incidence of myocardial ischemia and death after noncardiac surgery in patients at risk of coronary disease [96-98]. von Dossow and colleagues [99] investigated the influence of perioperative clonidine infusion on the early $\mathrm{T}$-cell immune response, in 


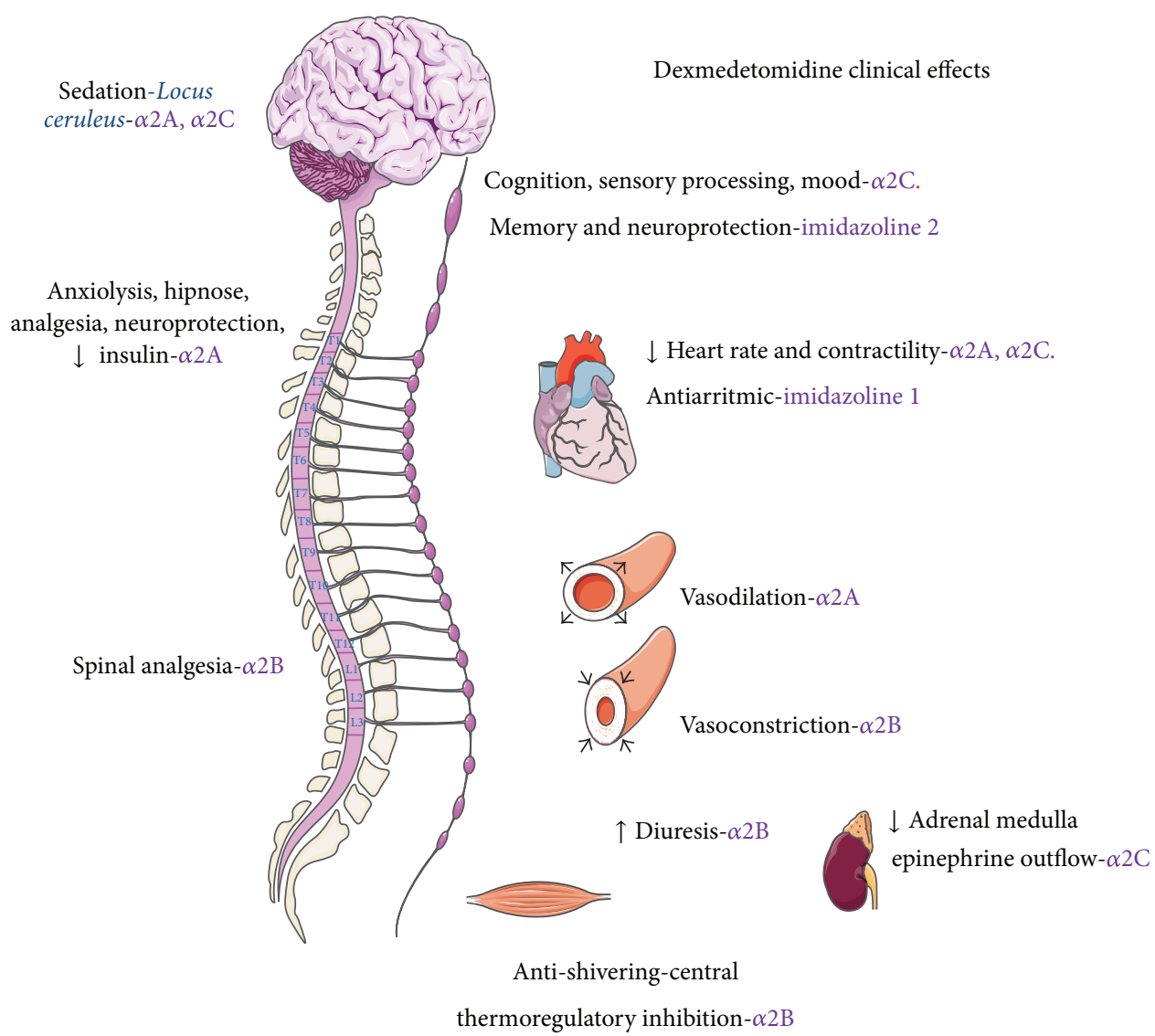

FIGURE 5: Dexmedetomidine clinical effects mediated via activation of $(\alpha$-)2-adrenergic and imidazoline receptors. Through the presynaptic $\alpha$-2A-adrenoreceptors agonism, dexmedetomidine induces sedation, anxiolysis, hipnose, analgesia, neuroprotection, reduces insulin release, reduces heart rate and contractility, producing vasodilation. In addition, agonistic effect on $\alpha-2 \mathrm{C}$ - adrenoreceptors induces sedation, mood and cognition modulation, sensorial processing, and reduction of adrenal medulla epinephrine. By the postsynaptic $\alpha$-2B-adrenoreceptors agonism, dexmedetomidine causes analgesia at spinal level, vasoconstriction (with high-bolus doses), improve of diuresis, and central inhibition of shivering. Dexmedetomidine acts also at imidazoline receptors, with a neuroprotection mechanism (imidazoline-2) and with antiarrhythmic effect (imidazoline-1).

patients undergoing elective coronary artery bypass graft surgery, and demonstrated early T-cell response ratios in the clonidine group $6 \mathrm{~h}$ after cardiac surgery. No differences were found with respect to plasma cytokine levels. In contrast to these findings, Ellis et al. [100] reported no influence of clonidine on lymphocytes but a significant decrease in plasma norepinephrine levels in patients undergoing major noncardiac surgery. The decreased norepinephrine plasma levels after clonidine administration have been previously reported [101], especially in patients undergoing cardiac surgery [102]. It has been hypothesized that the major effect of $(\alpha$-)2-adrenergic receptor agonists is on tonic activity, while sympathetic nervous system responsiveness to stressful stimuli appears to be unaffected.

Here it is important to emphasize that there are few studies about the modulation of inflammatory response after systemic use of clonidine in anesthesia. In a study with 7 patients, preoperative administration of clonidine was associated with a reduction in plasma and cerebrospinal fluid levels of TNF-alpha [103]. Similarly, perioperative epidural clonidine administration caused a decrease in blood IL-6 and suggested that $(\alpha$-)2-adrenergic receptor stimulation can modulate systemic inflammatory response in human [104].

3.2. Dexmedetomidine. Dexmedetomidine is a selective $(\alpha-)$ 2 -adrenergic receptor agonist with an increased ratio of $(\alpha-) 2$ to $(\alpha-) 1$ activity of $1.620: 1$, as compared to clonidine $(220: 1)$. In 1999, dexmedetomidine was approved by the United States of America (USA) Food and Drug Administration (FDA) only for sedation of patients. In 2008, based on two randomized, double-blind, placebo controlled, multicenter trials [105], FDA approved the update labeling use for dexmedetomidine, including the indication for sedation in surgery or other procedures.

Dexmedetomidine is the dextro enantiomer of medetomidine, the methylated derivative of etomidine, and specific $(\alpha-) 2$ adrenergic receptor subtypes mediate its pharmacodynamic effects (Figure 4). Agonism at the $(\alpha-) 2 \mathrm{~A}$ adrenergic receptor appears to promote sedation, hypnosis, analgesia, sympatholysis, neuroprotection [106], and inhibition of insulin secretion [107]. Agonism at the $(\alpha-)$ 2B adrenergic receptor suppresses shivering centrally [108] 


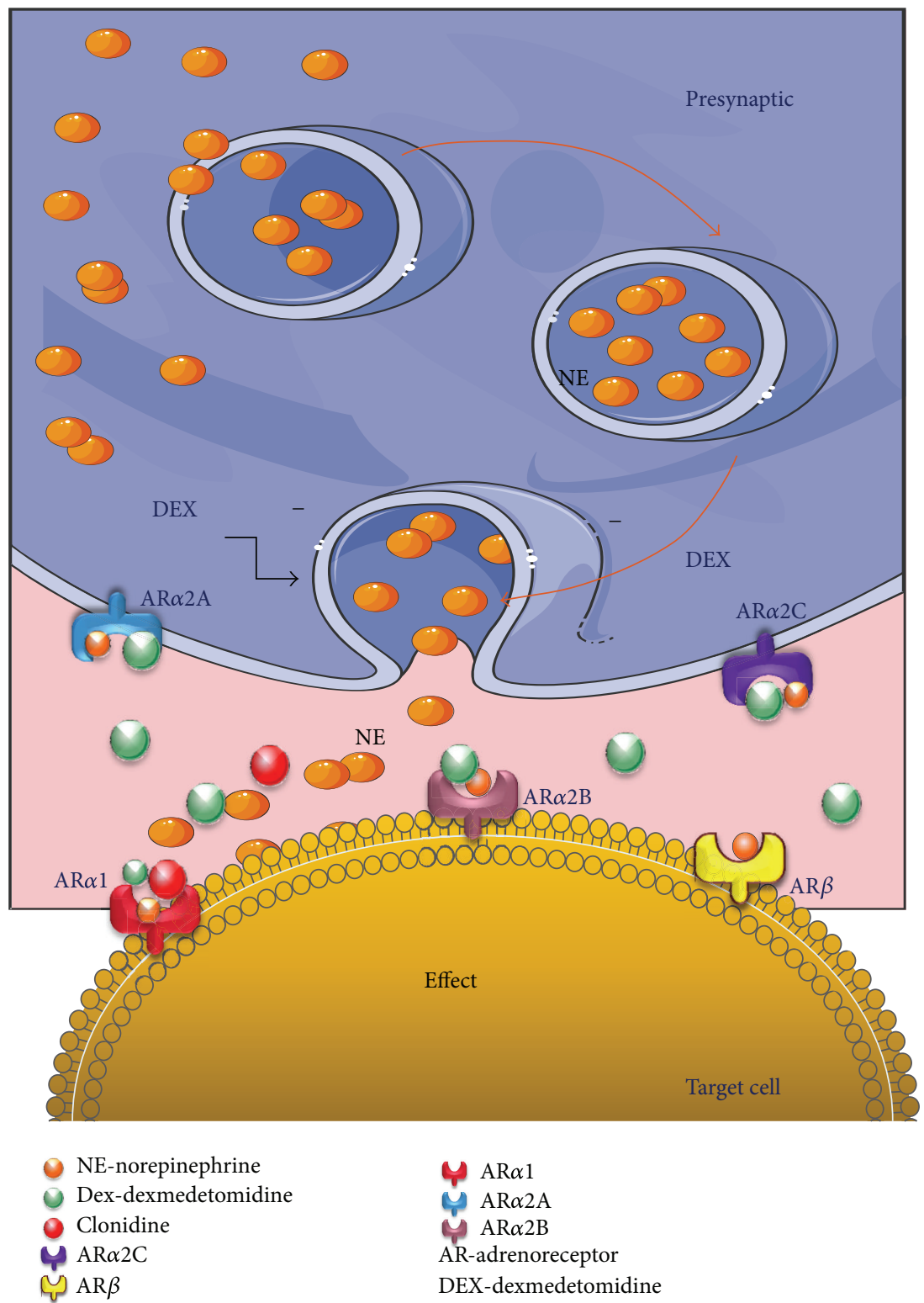

FiguRE 6: Dexmedetomidine can exert its effects via activation of three ( $\alpha$-)2-adrenoreceptor subtypes. A subclass of $(\alpha$ - $) 2$-adrenoreceptor located presynaptically $((\alpha-) 2 \mathrm{~A}$ and $(\alpha-) 2 \mathrm{C})$ regulated the release of neurotransmitter (norepinephrine). Located postsynaptically, a subclass of $(\alpha$-)2B-adrenoreceptor and also the $(\alpha$-)1-adrenoceptor, while dexmedetomidine is not $(\alpha$-)2-adrenoceptor selective. The $(\alpha$-)2adrenoceptors could exist also extrasynaptically.

and induces analgesia at spinal cord and vasoconstriction in peripheral arteries. The $(\alpha-) 2 \mathrm{C}$ adrenergic receptor is associated with cognition, sensory processing, mood, and regulation of epinephrine outflow from the adrenal medulla [109]. Inhibition of norepinephrine release appears to be equally affected by all three alpha-2 receptor subtypes [110] (Figure 6). Dexmedetomidine also binds to imidazoline receptors and this activity may explain some of the non- $(\alpha-)$ 2 adrenergic receptor effects of this drug, and receptor subtypes have also been identified. Imidazoline-1 receptors are linked to G-proteins and modulate blood pressure and have antiarrhythmic effects [90]. Imidazoline-2 receptors have been implicated in neuroprotection in a cerebral ischemia model in animals and in acquisition and retention of memory. They are not G-protein coupled receptors and are located on the mitochondrial outer membrane and probably exert their effects by decreasing tissue norepinephrine levels [90, 111].

3.2.1. Dexmedetomidine Pharmacokinetics. After intravenous injection, dexmedetomidine has an onset of action after 15 minutes and peak concentrations are achieved within 1 hour after continuous intravenous infusion. Rapid distribution occurs away from the central neurological system with an alpha half-life $\left(t_{1 / 2} \alpha\right)$ of 6 minutes and a terminal elimination half-life $\left(t_{1 / 2} \beta\right)$ between 2.0 and 2.5 hours. The drug is highly 
protein-bound, with a $6 \%$ free fraction, and has a large steady state volume of distribution $\left(V_{\mathrm{dss}}, 1.33 \mathrm{~L} \cdot \mathrm{kg}^{-1}\right)$. Total plasma clearance and protein binding is age independent [112].

Hepatic clearance may be decreased to $50 \%$ of normal with severe liver disease. Pharmacokinetics is not significantly altered in patients with severe renal impairment, but patients remained sedated for longer than normal controls, suggesting an enhanced pharmacodynamic effect [113]. Thus, dosages should be decreased in the presence of either hepatic or renal diseases. There are no recognized active or toxic hepatic derivatives of dexmedetomidine after its metabolism via glucuronide conjugation and biotransformation by cytochrome P450 enzymes.

Intravascular doses of dexmedetomidine induced dosedependent decreases in systolic and diastolic blood pressure and in heart rate with important decreases in plasma norepinephrine levels. However, at high-bolus intravascular doses $(50-75 \mu \mathrm{g})$, a transient initial hypertensive response may be seen, because an activation of peripheral vascular $(\alpha-) 2 \mathrm{~B}$ adrenergic receptors before the central sympatholytic effect on the vasomotor center occurs [114]. Dexmedetomidine apparently does not induce alterations in plasma renin activity, atrial natriuretic peptide, or arginine vasopressin levels [115].

Targeted plasma dexmedetomidine levels revealed desirable pharmacodynamic effects between 0.5 and $1.2 \mathrm{ng} \cdot \mathrm{mL}^{-1}$. Subsequent clinical studies designed to achieve these effects used a loading dose of $1 \mu \mathrm{g} \cdot \mathrm{kg}^{-1}$ during a period of 10 minutes, followed by a continuous intravenous infusion rate of 0.2 to $0.7 \mu \mathrm{g} \cdot \mathrm{kg}^{-1} \cdot \mathrm{h}^{-1}$, the dosing regimen originally approved by the USA Food and Drug Administration in 1999. Studies examining very high dexmedetomidine plasma levels (up to $8.0 \mathrm{ng} \cdot \mathrm{mL}^{-1}$ ) demonstrate that the $(\alpha-) 2 \mathrm{~B}$ peripheral vasoconstrictor effects become predominant, with increasing systemic vascular resistance and decreasing cardiac index, associated with marked catecholamine suppression and deepening sedation. Even at these very high plasma levels of dexmedetomidine, there was no clinically significant respiratory depression [116] and it appears to be safe. Case reports of large accidental overdoses of dexmedetomidine describe oversedation as the only important effect, with resolution within an hour of discontinuation [117]. There are reports of dexmedetomidine safe use as the sole agent at high rates of infusion $\left(5-15 \mu \mathrm{g} \cdot \mathrm{kg}^{-1} \cdot \mathrm{h}^{-1}\right)$ to anesthetize patients with tracheal stenosis while preserving spontaneous ventilation [118]. In October 2008, the US Food and Drug Administration approved an increased dose of dexmedetomidine (up to $1.5 \mu \mathrm{g} \cdot \mathrm{kg}^{-1} \cdot \mathrm{h}^{-1}$ ) for surgical procedures.

3.2.2. Dexmedetomidine Analgesic and Sedative Effects. Dexmedetomidine possesses analgesic properties and other advantageous pharmacological effects that make it a potential useful and safe adjunct in several clinical applications, as demonstrated by Sleigh in a recent review [119]. When used as an adjunct to general anesthesia, dexmedetomidine can reduce both the minimum alveolar concentration requirement of inhalation agents and provide opiate-sparing properties up to $90 \%[120]$.
The mechanism by which ( $\alpha$-)2-adrenergic receptor agonists produce analgesia and sedation is multifactorial. Both hypnotic and supraspinal analgesic effects of dexmedetomidine are mediated by noradrenergic neurons. Dexmedetomidine causes inhibition of norepinephrine release and its neuron associated activity in the descending medullospinal noradrenergic pathway and suppresses neuronal activity in the locus coeruleus [121]. Suppression of these inhibitory controls causes release of mediators and neurotransmitters that decrease the secretion of histamine and produce hypnosis, similar to normal sleep, without evidence of depression of ventilation [122]. The suppression of activity along the descending noradrenergic pathway terminates propagation of pain signals, resulting in analgesia or decreased awareness at noxious stimuli. In neurons of the superficial dorsal horn of the spinal cord, dexmedetomidine suppresses and reduces pain transmission by inhibiting the release of glutamate and substance $P$ (nociceptive transmitters) from primary afferent terminals and with G-protein-mediated activation of potassium channels causing hyperpolarization of interspinal, neurons. Antinociception may also be provided by nonspinal mechanisms, as demonstrated in intra-articular administration of dexmedetomidine during knee surgery, which was associated with improved postoperative analgesia, with less sedation than the intravenous route [123]. The suggested mechanisms are activation of alpha-2A adrenoreceptors [124] inhibition of the conduction of nerve signals through $\mathrm{C}$ and $A \delta$ fibers and the local release of encephalin. Figure 7 demonstrated the possible effector mechanisms of the $(\alpha-) 2$ adrenoreceptors, linked to $\mathrm{G}$ proteins.

Dexmedetomidine provides dose-dependent increases in anxiolysis and sedation that appears to be unique in comparison with GABAergic agents such as midazolam or propofol. Arousability is maintained at deep levels of sedation [125] and, once aroused, patients normally performed well the tests of vigilance [126], and they can cooperate with nursing, radiologic, and airway procedures [127]. There appears to be particular value in a drug such as dexmedetomidine that facilitates the arousal and rapid orientation of a sedated patient. The amnestic effects of dexmedetomidine are far less than the benzodiazepines, which provide profound anterograde amnesia that may contribute to confused states on emergence. In contrast, amnesia is achieved with dexmedetomidine only at high plasma levels $\left(\geq 1.9 \mathrm{ng} \cdot \mathrm{mL}^{-1}\right)$, without retrograde amnesia [116].

Unlike opioids, dexmedetomidine achieves its sedative, hypnotic, and analgesic effects without causing any clinically relevant respiratory depression, even when dosed to plasma levels up to 15 times those normally recommended for therapy [116]. Sedation induced by dexmedetomidine has the respiratory pattern and electroencephalogram (EEG) changes comparable with natural sleep. Compared with remifentanil, hypercapnic arousal is preserved [128] and functional magnetic resonance imaging studies show that unlike GABAergic agents dexmedetomidine preserves a cerebral blood flow pattern from natural sleep [129].

Administration of dexmedetomidine during sevoflurane or desflurane anesthesia with spontaneous ventilation has 


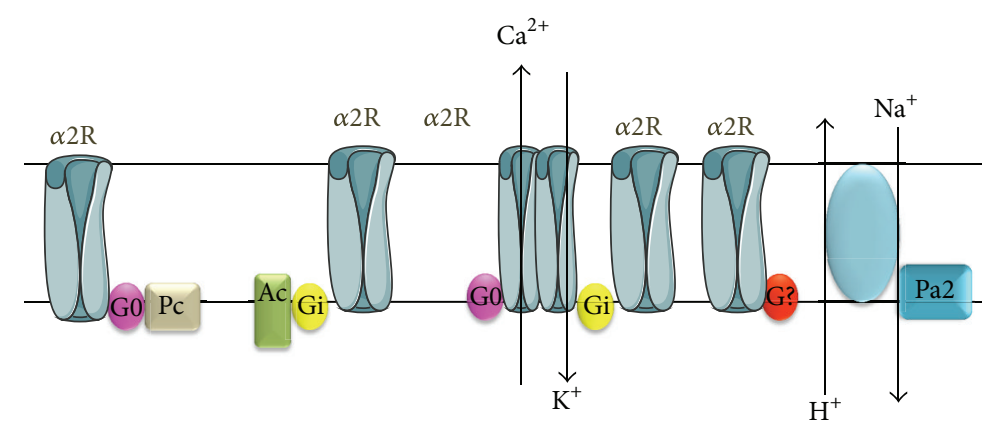

FIgURE 7: Putative intracellular mechanisms involved in the ( $\alpha$-)2-adrenoreceptors activation. The $(\alpha$-)2-adrenoreceptor subtypes are transmembrane receptors that can be coupled to different classes of G-protein. The activation of $(\alpha$-)2-adrenoreceptor $(\alpha 2 \mathrm{R})$ inhibits adenyl cyclase (Ac) via activation of receptor-coupled Gi protein. This causes outward opening of the $\mathrm{K}^{+}$channel via Gi protein, which results in cell hyperpolarization. The coupling of adrenoreceptors to $\mathrm{G} 0$ can either inhibit $\mathrm{Ca}^{2+}$ translocation or modulate phospholipase $\mathrm{C}$ (Pc). The coupling with an undetermined class of $\mathrm{G}$ protein $\left(\mathrm{G}\right.$ ?) stimulates an exchange of $\mathrm{H}^{+}$and $\mathrm{Na}^{+}$(Modified from [106]).

no effect on end-tidal carbon dioxide [130] and arterial saturation is better preserved with dexmedetomidine than propofol under magnetic resonance imaging procedures [131]. In contrast to infusions of opioids, benzodiazepines, or propofol, dexmedetomidine can safely be infused through tracheal extubation and beyond. It has been used successfully to facilitate tracheal extubation in patients who had previously failed extubation because of excessive agitation [132].

3.2.3. Anti-Inflammatory Effects of Dexmedetomidine. Reactive oxygen species (ROS) are considered as key regulatory molecules vital for life, but they cause cellular and organ damage when produced in excess or when antioxidant defenses are overwhelmed such in cardiac and neurologic ischemic and reperfusion injury. ROS can contribute to myocardial stunning, infarction, and apoptosis, to the genesis of arrhythmias and neurologic deficits. Several intravascular anesthetic drugs can act as reactive oxygen species scavengers. It was demonstrated in patients with impaired preoperative left ventricular function undergoing elective coronary artery bypass surgery with cardiopulmonary bypass, that the administration and maintenance of a clinically relevant dose of propofol from before aortic cross-clamp release, maintained until 4 hours after reperfusion, attenuate myocardial lipid peroxidation, associated with a decrease in IL-6 production and a late increase of IL-10 release [133].

Recently, Arslan and colleagues (2012) concluded that dexmedetomidine protected liver from lipid peroxidation, when given before induction of ischemia in an experimental model [134]. Rocha and colleagues have also indicated the protective potential of dexmedetomidine in women which underwent pelvic videolaparoscopic surgery [135]. In their study dexmedetomidine protected blood aminolevulinate dehydratase (ALA-D) from inactivation caused by hyperoxygenation in total intravenous anesthesia. The results of the investigation indicated that blood ALA-D from patients anesthetized with dexmedetomine was not modified by exposure to high concentrations of oxygen, whereas the activity of enzyme from those patients anesthetized with remifentanil exhibited a statistical significant decrease in activity. Regarding the dexmedetomidine group, it is possible that the anesthetic has protected the enzyme from oxidation by hyperoxygenation process.

Several investigators have published reports about the effects of dexmedetomidine and other $(\alpha$-)2-adrenergic receptors agonists on cytokines [136] and on $(\alpha$-)2-agonists modulated lipopolysaccharide-induced tumor necrosis factor- $\alpha$ production by macrophages [137]. Taniguchi and colleagues [138] demonstrated that dexmedetomidine has an inhibitory effect on cytokine responses to endotoxemia. These findings suggest that one of the mechanisms of anti-inflammatory effects of dexmedetomidine may be via modulation of cytokine production by macrophages and monocytes. Hofer and colleagues demonstrated that dexmedetomidine infusion decreased cytokine production in sepsis [139], which is in accordance with a recent study showing reno and pulmonary protective effect of dexmedetomidine in an experimental model of sepsis in rats [33]. They have shown that preventive administration of clonidine or dexmedetomidine improved survival in induced sepsis. This was accompanied by a reduction in the proinflammatory mediators IL-1 $\beta$, IL-6, and tumor necrosis factor- $\alpha$. Furthermore, they suggested that administration of a central acting ( $\alpha$-)2-adrenoreceptor agonist might be considered as a preventive therapeutic option in high-risk patients undergoing major surgery. In another animal study, dexmedetomidine treatment was equally effective to methylprednisolone in reducing TNF- $\alpha$ and IL- 6 levels induced by spinal cord injury. Apparently, dexmedetomidine treatment reduced neutrophils' infiltration at the site of spinal cord injury [140]. Dexmedetomidine inhibited cortisol synthesis at supratherapeutic concentrations but this has not been reported in short-term use in humans [141, 142]. Our study group have the influence of dexmedetomidine on cortisol levels studied [143]. At this study, we measured cortisol concentrations before anesthetic induction, 5 minutes after intubation, and 30 minutes after surgical incision in patients undergoing gynecologic videolaparoscopic surgery, receiving dexmedetomidine 
or remifentanil. After intubation, there was a significant decrease in cortisol concentrations from baseline in both groups $\left(-4.3 \pm 1.4 \mu \mathrm{g} \cdot \mathrm{dL}^{-1}\right.$ and $-4.6 \pm 1.6 \mu \mathrm{g} \cdot \mathrm{dL}^{-1}$, resp.) but only in the remifentanil group at 30 minutes after incision $\left(2.6 \pm 1.8 \mu \mathrm{g} \cdot \mathrm{dL}^{-1}\right.$ and $\left.-7.1 \pm 2.1 \mu \mathrm{g} \cdot \mathrm{dL}^{-1}\right)$ and we could conclude that dexmedetomidine did not suppress steroidogenesis [143]. In the MENDS trial [144], cortisol concentrations were determined at baseline and 2 days after stopping dexmedetomidine infusion, and there was no statistically significant difference in cortisol concentrations. At high doses as $1.5 \mu \mathrm{g} \cdot \mathrm{kg}^{-1} \cdot \mathrm{h}^{-1}$ dexmedetomidine does not appear to cause clinically significant adrenal suppression [145].

Laryngoscopy and endotracheal intubation also provoke marked sympathetic and sympathoadrenal response that increase the risk of perioperative myocardial ischemia and infarction. The perioperative use of dexmedetomidine may improve endocardial perfusion and decrease heart rate with attenuation of stress response [146]. Dexmedetomidine increases the hemodynamic stability by altering the stressinduced sympathoadrenal responses to intubation, during surgery and emergence from anesthesia [147] and this reflects a better outcome.

In a recent study, Sukegawa and colleagues [148] described the potent inhibitory effect of dexmedetomidine on inflammatory reactions, including edema, accumulation of inflammatory cells, and production of tumor necrosis factor-alpha and cyclooxygenase-2 (COX-2), induced by an injection of carrageenan into the paw of mice. They have also demonstrated a potent anti-inflammatory effect of dexmedetomidine at a high dose on endotoxin-induced inflammation in murine macrophages [149].

Yagmurdur and colleagues [150] have examined the effect of dexmedetomidine on ischemia/reperfusion injury due to tourniquet during upper-extremity surgery by determining blood malondialdehyde and hypoxanthine levels. Dexmedetomidine significantly attenuated plasma hypoxanthine production in the ischemia and plasma malondialdehyde production in the reperfusion periods. They suggest that dexmedetomidine can have advantages over other anesthetic agents (for instance, opioids and propofol) by inhibiting lipid peroxidation in the case of anticipated ischemia/reperfusion injury, such as that would occur in upper-extremity surgery requiring tourniquet application. Bekker and colleagues [151] hypothesized that the intraoperative administration of dexmedetomidine could reduce the stress response and improve the quality of recovery in patients undergoing major spinal surgery. They compare a propofol/fentanil/dexmedetomidine anesthesia group with propofol/fentanil/placebosaline anesthesia. In both groups, plasma cortisol levels were elevated in the postanesthesia care unit, whereas C-reactive protein levels were elevated only in the first postoperative day. Dexmedetomidine significantly reduced the levels of cortisol but not those of C-reactive protein. Levels of cytokines IL- 6 and IL-8 were significantly higher immediately after surgery and at first postoperative day. Dexmedetomidine delayed postoperative rise of IL-10 but not of IL-6 or IL-8. Plasma levels of other cytokines were not affected by surgery. Clinically, dexmedetomidine infusion moderately improved the quality of recovery [105].

$\mathrm{Gu}$ and colleagues also conducted a study [152] to investigate dexmedetomidine anti-inflammatory capacity. They utilized an animal model of renal ischemia/reperfusion that induced an acute lung injury and either pretreated mice with dexmedetomidine ( $25 \mu \mathrm{g} \cdot \mathrm{kg}^{-1}$ before ischemia) or gave it after reperfusion. Renal ischemia/reperfusion induced an increase of inflammatory markers in lungs (myeloperoxidase (MPO) activity, intercellular adhesion molecule-1 (ICAM1 ), and TNF- $\alpha$ mRNA level). Both pre- and posttreatment with dexmedetomidine markedly reduced lung edema and inflammatory response and lowered MPO activity and ICAM- 1 and TNF- $\alpha$ mRNA expression. Other study explored the anti-inflammatory effects of dexmedetomidine in rats, using an intravenous infusion of dexmedetomidine at the rate of $5.0 \mu \mathrm{g} \cdot \mathrm{kg}^{-1} \cdot \mathrm{h}^{-1}$ after bilateral blunt chest traumainduced pulmonary contusion [153]. Dexmedetomidine not only significantly modified hemodynamics and relieved the infiltration of inflammatory cells into alveolar spaces but also inhibited the injury-induced increase in plasma TNF- $\alpha$ and IL- $1 \beta$ production.

In humans, Kang and colleagues [154] demonstrated the anti-inflammatory dexmedetomidine effects in patients subjected to laparoscopic cholecystectomy. Patients in the dexmedetomidine group received a loading dose of dexmedetomidine $\left(1.0 \mu \mathrm{g} \cdot \mathrm{kg}^{-1}\right)$, followed by infusion of dexmedetomidine at $0.5 \mu \mathrm{g} \cdot \mathrm{kg}^{-1} \cdot \mathrm{h}^{-1}$. Dexmedetomidine decreased the plasma level of IL-1 $\beta$, TNF- $\alpha$, and IL-10, when compared to saline group. The C-reactive protein (CRP) level and leukocyte count on postoperative day 1 were also lower in dexmedetomidine group. Tasdogan and colleagues [155] conducted another study to compare the effects of an intravenous infusion of propofol and dexmedetomidine, on inflammatory responses and intra-abdominal pressure in severe sepsis after abdominal surgery. Dexmedetomidine infusion decreases tumor necrosis factor-alpha, IL-1, and IL6 levels and intra-abdominal pressure significantly more than a propofol infusion.

3.2.4. Neuroprotective Effects of Dexmedetomidine. The brain has a high requirement for oxygen and glucose but is unable to store these substrates and rapid necrosis occurs to hypoxic-ischemic injury. It results in dysfunction of adenosine triphosphate (ATP) dependent ion channels and pumps, leading to cellular depolarization and the release of extracellular excitatory neurotransmitters. The most important neurotransmitter is glutamate, which activates the $\mathrm{N}$ methyl-D-aspartate receptor (NMDA), increasing intracellular calcium and sodium, contributing further to depolarization and neuronal activation. Excess of calcium promotes activation of pathways which disrupt ionic homeostasis, leading to membrane degeneration and excitotoxic cell death [156]. Apoptotic mechanisms are also activated in response to ischemic brain injury, days to weeks after ischemic insult, especially in the region surrounding the necrotic area [157].

Neurological injury remains a major cause of morbidity in cardiac surgery patients and, in an extensive review, 
Hogue Jr and colleagues [43] concluded that about $60 \%$ of patients have evidence of cognitive decline one month after cardiac surgery. Central nervous system deficits after cardiopulmonary bypass ranging from postoperative cognitive dysfunction (POCD), with incidence of $30-60 \%$ [158, 159] to stroke, over $1-5 \%$ of patients [160]. Adverse cerebral outcomes after cardiac surgery have been studied for a long time and literature data suggest that modalities modifying the systemic inflammatory response to cardiopulmonary bypass might protect brain against potential injury after cardiac surgery $[44,45,161]$. But the association between cardiopulmonary bypass-induced inflammation and neurocognitive deficits itself remains less than clear. A review of the literature did not support neurocognitive decline after cardiopulmonary bypass as a result of an exacerbated inflammatory response initiated by extracorporeal circulation. In recent issue, Jungwirth and colleagues [61] have published a well-controlled study in a rat model that fails to demonstrate a relationship between neurologic injury and the foreign surface area of cardiopulmonary bypass or donor blood used to prime the cardiopulmonary pump. They have suggested that other factors than cardiopulmonary bypass lead to adverse neurocognitive outcomes after cardiac surgery. Elsewhere, neurocognitive impairment in many patients undergoing cardiac surgery may be preexisting, although subclinical $[62,162-166]$, and the cognitive outcomes for patients needing cardiac surgery with cardiopulmonary bypass appear to depend little on the perfusion technique, but rather on the underlying diseases [167]. However, inflammatory response, oxidative stress, and massive extracellular catecholamine release may lead to additional neurodegeneration [167].

Nevertheless, Singh and colleagues [168] concluded that anesthetic choice in patients under cardiac surgery may have implications on S100B protein serum levels, a neuroinflammatory component, that could be a marker for brain injury on serum [169] and/or damage to blood-brain barrier [76]. In other trials $[144,170,171]$, patients receiving dexmedetomidine developed significantly less delirium compared with patients receiving other drugs, such as midazolam or propofol in intensive central unit. The pathogenesis of postoperative delirium is not completely clear but appears to be related, in part, to increased release of inflammatory mediators and the binding to the gamma-aminobutyric acid (GABA) receptor [171]. Dexmedetomidine does not bind to the GABA receptor and hence may minimize the development of delirium by decreasing release of norepinephrine. Because of conflicting results [172] more studies are needed to determine whether dexmedetomidine can really prevent or treat postoperative associated delirium. Many anesthetics act as gammaaminobutyric acid (GABA) receptor agonists, and in animal models, a GABA agonist can suppress neural cell proliferation, whereas GABA antagonist can enhance neurogenesis $[173,174]$. Dexmedetomidine acts by reducing noradrenergic output from the locus coeruleus, and decreasing brain norepinephrine levels, and in animals, manipulations that decrease brain norepinephrine also suppress cell proliferation $[175,176]$. Inhaled anesthetics such as isoflurane inhibit the cholinergic basal forebrain and suppress hippocampal neurogenesis in animals [177]. However, Tung and colleagues
[178] found no effect of prolonged (8 hours) anesthesia with isoflurane, propofol, or dexmedetomidine on hippocampal cell proliferation in 3- or 12-month-old Sprague-Dawley rats. These results suggest that the sum of the many potential mechanisms linking cell proliferation to the anesthetized state (vigilance state, environmental stimuli, adrenal effects of anesthesia, and direct pharmacologic effects) results in no overall effect and that suppression of adult hippocampal cell proliferation is unlikely to be an effect of brief or prolonged anesthesia, and thus unlikely to cause postoperative cognitive dysfunction in humans.

The neuroprotective effects of dexmedetomidine have been also demonstrated in vivo and in vitro in a variety of models of ischemia. These include models of incomplete ischemia in the rat $[179,180]$, transient focal ischemia in rabbits [181], and transient global ischemia in gerbils [182]. In vitro studies of neuronal injury, using hippocampal slices [183] and neuronal and cortical cell cultures [184] also support dexmedetomidine as a neuroprotectant drug.

Originally, all dexmedetomidine neuroprotective activities were supposed to be caused by inactivation of presynaptic $(\alpha$-)2-adrenergic receptors, inhibiting noradrenergic activity. However, dexmedetomidine concentrations well below $100 \mathrm{nM}$ exert prominent effects on cultured astrocytes [184, $185]$ and the $(\alpha$-)2-adrenoceptor is densely expressed in astrocytes freshly isolated from mouse brain by fluorescenceactivated cell sorting [186]. Thus, instead of receiving a subtype-mixed noradrenergic signal from locus coeruleus the cells can be directly activated at their $(\alpha$-)2-adrenoceptor sites by the drug.

The $(\alpha$-)2-adrenergic signaling pathway has been studied in cultured astrocytes $[185,187]$. It connects activation of $(\alpha-)$ 2 -adrenoceptors with extracellular signal-regulated kinase (ERK) phosphorylation in two stages, separated by transactivation of the epidermal growth factor (EGF) receptor. This receptor is highly expressed in both neurons and astrocytes. In the first stage, the $\beta \gamma$ subunits of the activated heterotrimeric Gi protein lead, via activation of cytosolic Src tyrosine kinases, to metalloproteinase-mediated "shedding" of heparin-binding epidermal growth factor (HB-EGF) from its transmembrane-spanning HB-EGF precursor. In the second stage, released HB-EGF "transactivates" EGF receptors in the same and adjacent cells (including neurons) by phosphorylating EGF receptors, leading to Ras- and Rafdependent ERK phosphorylation [185, 187]. The astrocytic effects may contribute also to dexmedetomidine's analgesic effects, at least in the spinal cord $[188,189]$ (Figure 8).

Despite dexmedetomidine has repeatedly been found to have neuroprotective effects against ischemia in experimental models [190] and could be able to protect against trauma in hippocampal organotypic cultures [191], these neuroprotection capacity has not been confirmed clinically.

More recently, Zhang and colleagues [192] described a possible mechanism through which dexmedetomidine induces neuroprotection. Based on knowledge that oxidative damage contributes greatly to posttraumatic brain injury [193] they induced oxidative neuronal injury with $\mathrm{H}_{2} \mathrm{O}_{2}$ in the glutamatergic cerebellar granule neurons. The hypothesis was tested that "conditioned" medium from 

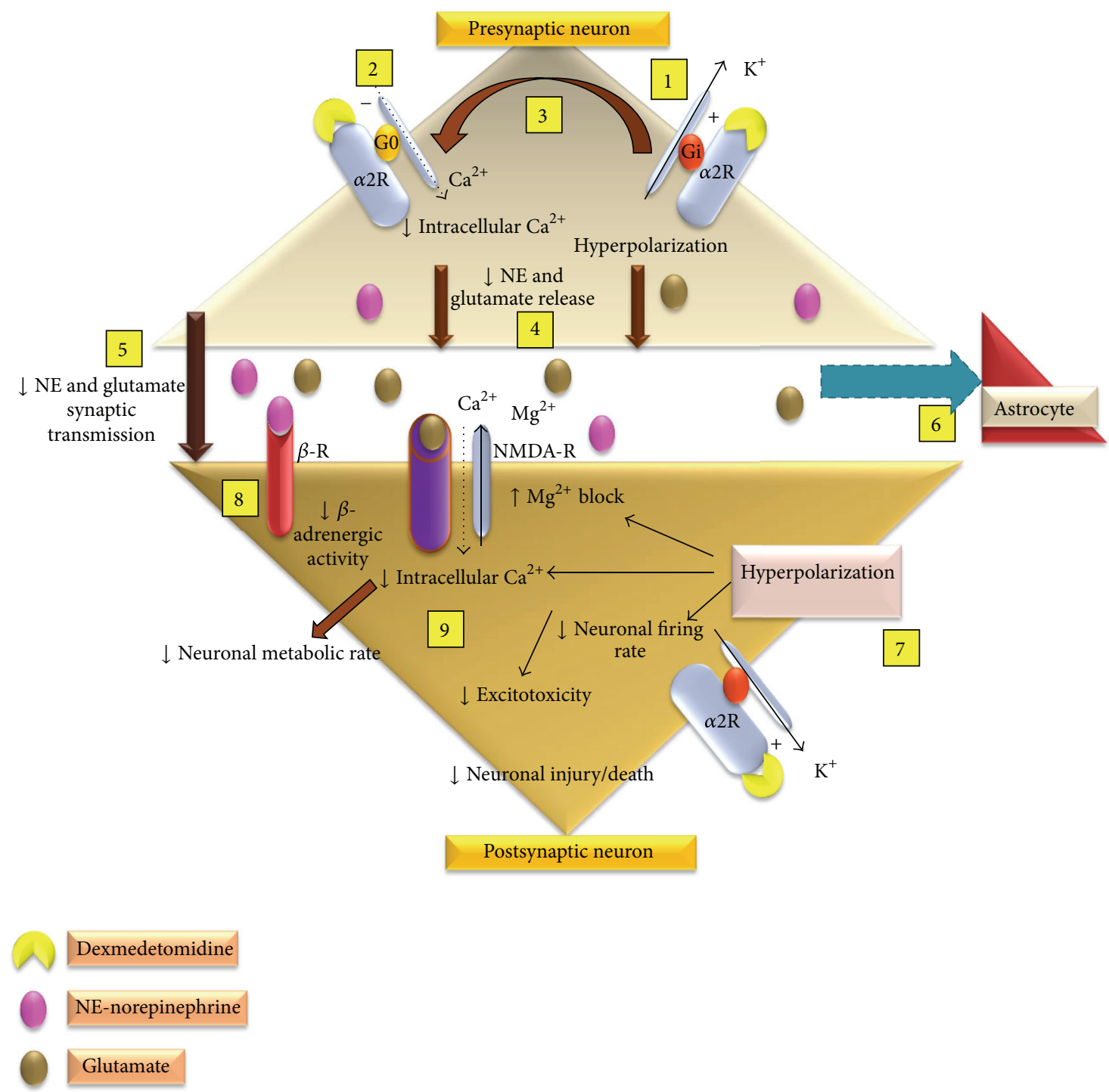

FIGURE 8: Neuroprotective mechanism(s) triggered by ( $\alpha$-)2-adrenoreceptors agonists. Presynaptically: (1) activation of outward rectifying K ${ }^{+}$ channels causing hyperpolarization; (2) inhibition of inward translocation of $\mathrm{Ca}^{2+}$ ions; (3) hyperpolarization resulting from action-1 causes reduced $\mathrm{Ca}^{2+}$ entry; (4) reduced intracellular $\mathrm{Ca}^{2+}$ (as a result of actions 2 and 3) causes diminished neurotransmitter release. Synaptically: (5) due to action-4 as well as reduced receptor sensitivity; (6) extrasynaptic scavenging of glutamate by astrocytes. Postsynaptically: (7) hyperpolarization reduces the activation of NMDA receptors by enhancing $\mathrm{Mg}^{2+}$ block and also causes reduced neuronal firing and reduced intracellular $\mathrm{Ca}^{2+}$ release; (8) due to actions 5 and 9. The reduced excitotoxic neuronal death due to combination of all actions but the main pathway is via a reduction in the free intracellular $\mathrm{Ca}^{2+}[106]$ (Modified of [157]).

dexmedetomidine-treated astrocyte cultures would enhance neuronal viability due to release of an epidermal growth factor (EGF) receptor agonist, whereas direct administration of dexmedetomidine to neurons or treatment with nonconditioned medium would have no effect. Furthermore, it was examined if the protection found after addition of medium from dexmedetomidine treated astrocytes was abolished by treatment of the astrocytes with the specific $(\alpha-)$ 2 -adrenergic antagonist atipamezole. This was confirmed, but atipamezole addition directly to $\mathrm{H}_{2} \mathrm{O}_{2}$-exposed neurons treated with dexmedetomidine had no effect. They demonstrated that dexmedetomidine at clinically relevant concentrations was neuroprotective against oxidative damage by stimulating directly the astrocytic ( $\alpha$-)2-adrenoceptors, causing release of heparin-binding epidermal growth factor (HB-EGF). HB-EGF in turn activates neuronal epidermal growth factor (EGF) receptors. At these concentrations, however, dexmedetomidine has no direct neuronal effect [192].

The practice of neuroprotection is difficult because the process of neuronal damage and cell death is complex and not completely understood. The complexity of pathophysiologic mechanisms suggests that neuroprotection may have a multimodal approach and it is unlikely that a single pharmaceutical agent will be effective in improving neurological outcome. Recent evidence indicates indeed that new neurons 
are produced in the adult hippocampus [194] and play a functional role in cognitive processes such as learning and memory $[195,196]$. Because anesthetics also affected these factors, it can be suspected that anesthetics or the anesthetized state also affected adult hippocampal cell proliferation. Anesthetic management may thus improve the quality of recovery in patients undergoing coronary artery bypass graft surgery, affecting the postoperative course, reduce the stress response, and possibly reduce neurological deficits onset.

\subsubsection{Dexmedetomidine as Protective Agent against Ischemia.} Regarding the cerebral circulation in humans, during cardiopulmonary bypass, relatively little information was available until Henriksen and colleagues [197] reported evidence of cerebral hyperemia in 1983. In 1984, Govier and colleagues [198] incite controversy and debate with their observations of ischemic threshold levels of cerebral blood flow during cardiopulmonary bypass. Murkin and colleagues [199], subsequently, reported a decrease in cerebral blood flow and metabolic rate (oxygen consumption) during hypothermic cardiopulmonary bypass in humans. These low values were restored to control levels shortly after separation from cardiopulmonary bypass system. This study demonstrated a physiological basis for the embolic theory of central nervous system impairment after cardiac surgery. Ganushchak and colleagues [200] tested with a retrospective study the hypothesis that combinations of hemodynamic events from apparently normal cardiopulmonary bypass procedures are related to the development of postoperative neurological complications and affect the impact of patient common clinical risk factors on postoperative neurological complications. Patients who underwent cardiopulmonary bypass procedures with large fluctuations in hemodynamic parameters particularly showed an increased risk for the development of postoperative neurological complications [200].

There are increasing points of evidence both in vitro and in vivo which indicates that dexmedetomidine has a cell-protective effect on nervous tissue under ischemic conditions [201-204]. Considering that ischemia enhances the formation of reactive oxygen species in brain tissue and the activation of brain cells as microglia to synthetize cytokines, Eser and colleagues [205] investigated the neuroprotective effects of dexmedetomidine on an animal model of transient global cerebral ischemia/reperfusion injury. They showed a lower number of apoptotic neurons at hippocampus and decreased levels of cytokines on dexmedetomidine group as compared to the saline control group. These results indicated a clear neuroprotective effect of dexmedetomidine after transient global cerebral ischemia/reperfusion injury.

In a recent review, Afonso and Reis [206] observed that dexmedetomidine seems to have promising applications on neuro- and cardioprotection and may confer this protection by targeting a number of different areas. The attenuation of ischemia-elicited increase in blood catecholamine levels and a limitation of excitotoxicity from glutamate might be involved in the protective underlying mechanism of dexmedetomidine. But more evidence has been obtained suggesting that this effect can be mediated also by the stimulation of imidazoline receptors [207]. The signal transduction cascade linked to these receptors comprises extracellular signal-regulated protein kinases 1 and 2 and is known to be an important regulator for cell survival and mediator of neuroprotective effects of various agents [208]. Dexmedetomidine was reported also to be effective in protecting against focal ischemia in rabbits, in cardiac ischemia/reperfusion injury in rats, in kidney ischemia/reperfusion injury in rats, and in incomplete forebrain ischemia in rats $[201,209,210]$.

There is considerably more experimental evidence that dexmedetomidine has neuroprotective effects by sympatholysis, preconditioning, and attenuation of ischemia/reperfusion injury [111] and under decreases on cerebral blood flow [211-213] with its ratio with cerebral metabolic rate to be preserved [214].

Schoeler and colleagues [215] found that dexmedetomidine has a protective effect on hippocampal slice cultures subjected to a focal mechanical trauma, with the observed trauma reduction being significantly more pronounced than observed in slices treated with hypothermia. But other studies have indicated conflicting results [216]. These authors investigated twenty-four patients, aged 50-70 years, undergoing coronary artery bypass graft surgery, randomized into two groups: those receiving dexmedetomidine (group D) and those which did not receive it (group C). As basal blood samples from arterial and jugular bulb catheters were drawn, dexmedetomidine $\left(1 \mu \mathrm{g} \cdot \mathrm{kg}^{-1}\right.$ bolus and infusion at a rate of $\left.0.7 \mu \mathrm{g} \cdot \mathrm{kg}^{-1} \cdot \mathrm{h}^{-1}\right)$ was administered to patients in group D. Arterial and jugular venous blood gas analyses, serum S-100B protein (S-100B), neuron-specific enolase (NSE), and lactate measurements were performed after induction, 10 minute after the initiation of cardiopulmonary bypass, 1 minute after declamping, at the end of cardiopulmonary bypass, at the end of the surgery, and at 24 hours after surgery. No significant differences between-groups were found regarding arterial and jugular venous $\mathrm{pH}, \mathrm{PO}_{2}, \mathrm{PCO}_{2}$, and $\mathrm{O}_{2}$ saturations. S$100 \mathrm{~B}$, NSE, and lactate levels were also similar between groups $\mathrm{D}$ and $\mathrm{C}$. During the postoperative period, there were no clinically overt neurological complications in any patient. Cerebral ischemia marker (S-100B, NSE and lactate) patterns were increased during cardiopulmonary bypass, as expected; however, there were no differences between the groups, which led to believe that during coronary artery bypass graft surgery dexmedetomidine has no neuroprotective effects [216].

At peripheral level, in spinal cord, dexmedetomidine can preserve neurologic function in mice after aortic crossclamping, as demonstrated by Bell and colleagues [217]. It was also observated that mice exhibited almost complete reversal of the protective effect with the administration of the $(\alpha)$-2A receptor antagonist atipamezole. Dexmedetomidine appears to attenuate spinal cord ischemia/reperfusion injury via $(\alpha-) 2 \mathrm{~A}$ receptor-mediated agonism [217].

At renal site, $\mathrm{Gu}$ and colleagues investigated whether the $(\alpha$-)2-adrenoceptor agonist dexmedetomidine provides protection against ischemia/reperfusion induced kidney injury in vitro and in vivo [218]. Pre- or posttreatment 
with dexmedetomidine provided cytoprotection, improved tubular architecture and function following renal ischemia. Associated with this cytoprotection, dexmedetomidine reduced plasma high-mobility group protein B1 (HMGB-1) elevation when given prior to or after kidney ischemia/ reperfusion, and pretreatment also decreased toll-like receptor 4 (TLR4) expression in tubular cells. Dexmedetomidine treatment promoted long-term functional renoprotection and even increased survival following nephrectomy. However, prospective human studies establishing a benefit of dexmedetomidine against kidney damage are not yet available.

Despite its increased clinical use and potential benefits, the effect of dexmedetomidine on inflammation and neuroprotection remains limited and somewhat controversial. Future investigators may examine the clinical benefits of the use of dexmedetomidine, and the correlation of better neurological outcome with anesthesia choice.

3.2.6. Dexmedetomidine Hemodynamic and Myocardial Protective Effects. Dexmedetomidine has complex hemodynamic effects specific to its activation of pre- and postsynaptic $(\alpha$-)2-adrenergic receptors. These effects are dose-dependent and biphasic: vasodilation at lower dosages, vasoconstriction at higher dosages, and an initial short-term increase in blood pressure followed by a longer lasting reduction in blood pressure and heart rate. Several investigations have identified the cardiovascular effects of dexmedetomidine [116, 219, 220]; however its effect on intraoperative hemodynamics during a propofol-supplemented remifentanil-based anesthesia regimen, which produces a strong vasodilatory effect, has not been well investigated.

There is a latent risk for excessive bradycardia and even sinus arrest when dexmedetomidine is administered in combination with sympatholytic or cholinergic agents (betablockers, fentanyl, and neostigmine), especially with concomitant vagal stimulation (sternal separation) [221-223]. Dexmedetomidine causes dose-dependent decreases in heart rate and blood pressure, concomitant with decreasing plasma catecholamines. This is of considerable benefit in tachycardic, hypertensive patients with improvement of hemodynamic stability in the perioperative period. These effects, however, may be unwanted in patients with congestive heart failure, whose cardiac output is rate dependent, or with conduction system disease. As mentioned, a high-dose bolus may result in a biphasic response, with bradycardia and hypertension consequent to initial stimulation of peripheral $(\alpha-) 2 \mathrm{~B}$ vascular receptors, followed by central sympatholysis and a decline in blood pressure [224]. Unlike clonidine, cessation of dexmedetomidine administration does not appear to be associated with rebound hypertension or agitation.

The ability of $(\alpha-) 2$ receptor agonists to decrease tachycardia and hypertension suggests that they may play a role in cardioprotection by enhancing myocardial oxygen balance. There is little evidence that dexmedetomidine could enhance myocardial ischemic preconditioning or attenuates reperfusion injury, for example, when used after cardiac surgery; dexmedetomidine decreased the incidence of ventricular arrhythmias from 5\% to zero, compared with propofol [116]. Other authors have described the safe use of dexmedetomidine as an anesthetic adjunct in coronary artery bypass grafting, improving a stable hemodynamic status [225, 226].

Guo and colleagues [226] investigated the protective effects of dexmedetomidine on left ventricular contractile performance under myocardial hypoxia. They study indicates that hypoxia immediately impairs left ventricular function with a rapid increase in coronary flow followed by a gradual decrease, with poor recovery of left ventricular function at reoxygenation. Dexmedetomidine administration only in prehypoxia improves recovery of left ventricular function and coronary flow, and the protective effects are antagonized by yohimbine. The mechanisms are not clear, but there are several possibilities.

Dexmedetomidine might exert the protective effect on left ventricular dysfunction through inhibition of the release of norepinephrine as suggested also by Chen and colleagues [227] that showed that the postischemic heart had a large amount of coronary norepinephrine overflow and that its reduction significantly improved the recovery of postischemic left ventricular function in an isolated working heart preparation. As demonstrated before, it is believed that high interstitial concentrations of norepinephrine result in myocyte calcium overload and cell death causing development of cardiac dysfunction [228]. The high plasma concentrations of catecholamines (norepinephrine and epinephrine) would lead to a calcium overload into the myocardial cells, increased cytosolic and intramitochondrial calcium, reactive oxygen species release, and adenosine triphosphate (ATP) depletion, with resulting electrocardiogram (ECG) changes, failing in myocardial contraction and possible cell death $[229,230]$. In patients under extreme sympathetic discharge caused by an acute stress a tissue lesion characterized by contraction of sarcomeric myofibrilles and interstitial mononuclear infiltration was described [231]. Ebert and colleagues [116] reported that dexmedetomidine diminished the hemodynamic and norepinephrine response to the activation of cardiac sympathetic nerves by the cold pressor test. Dexmedetomidine could also prevent a myocardial ischemiainduced norepinephrine release in anesthetized dogs [232].

Dexmedetomidine increases the cyclic adenosine monophosphate (cAMP) level in the coronary artery. Guo and colleagues [226] demonstrated that hypoxia caused an immediate increase in coronary flow followed by a gradual decrease, similarly to the results of Karamazyn and colleagues [233], and reoxygenation resulted in poor recovery. Pinsky and colleagues [234] reported that the graft vasculature with hypoxia impaired vascular function and decreased blood flow after transplantation, and it enhanced phosphodiesterase activity and caused a time dependent decline in cAMP levels in the vascular smooth muscle cells. Kitakaze and colleagues [235] reported that an increase in cAMP level by stimulation of adenosine receptors was amplified by the $(\alpha$ - $) 2$-adrenergic stimulation in the coronary artery. Thus it is possible that dexmedetomidine could increase the cAMP level and attenuate coronary vascular damage of an adenosine-induced coronary vasodilative effect and preserve coronary flow. Kitakaze and 
colleagues [235] provided evidence that alpha-2-adrenergic stimulation increased coronary flow during ischemia as a result of enhancement of adenosine-induced coronary vasodilation, although $(\alpha$-)2-adrenergic stimulation exerted prominent vasoconstriction in nonischemic hearts. However, in Guo study, dexmedetomidine did not significantly improve the coronary flow during hypoxia, contesting this hypothesis.

A large European study demonstrated that perioperative infusion of mivazerol, another $(\alpha$-)2-adrenergic agonist, significantly decreased cardiac death after vascular surgery in patients with known coronary artery disease [236]. And a meta-analysis of noncardiac vascular surgery patients receiving any $(\alpha$-)2-adrenergic agonist agent demonstrated decreased risk of myocardial infarction and death [237], but dexmedetomidine alone on cardiovascular outcomes after noncardiac surgery did not show statistical significance [238]. Therefore, larger studies are required to clearly ascertain the cardioprotective effect of dexmedetomidine and whether or not it should be included in patients at high cardiac risk.

3.2.7. Dexmedetomidine Other Potential Effects. The effects of dexmedetomidine on renal function are complex. Alpha2 agonists exert a diuretic effect with decreased salt and water reabsorption [239]. There are experimental evidence that dexmedetomidine attenuates murine radiocontrast nephropathy by preserving cortical blood flow [240]. This mechanism is supported by the observation that dexmedetomidine decreases the renal cortical release of norepinephrine [210]. There are also evidence that dexmedetomidine attenuates murine ischemia/reperfusion injury [170]. However, prospective human studies cannot establish renal benefits of dexmedetomidine.

Based on preliminary studies, the USA Food and Drug Administration approved that duration of infusion of dexmedetomidine remains 24 hours. However, there are several studies that have demonstrated safe use for a week or longer in mechanically ventilated critically ill patients [241]. With prolonged administration, tolerance to dexmedetomidine's hypnotic effects has been demonstrated in animals [242], but it does not appear to be clinically significant.

Dexmedetomidine also suppresses shivering, possibly by their activity at $(\alpha-) 2 \mathrm{~B}$ receptors in the hypothalamic thermoregulatory center of the brain [243]. Low-dose dexmedetomidine has an additive effect with meperidine on lowering the shivering threshold, when these drugs are combined [244]. Dexmedetomidine may be beneficial in decreasing patient discomfort and oxygen consumption that occur on postoperative shivering [245].

Alpha-2 adrenergic agonists, such as clonidine, have also an established role in the treatment of central hyperadrenergic states induced by withdrawal of drugs, including cocaine, alcohol, or opioids. Numerous case reports of successful treatment of withdrawal using dexmedetomidine have been published [224, 246-249], but, to date, no randomized trials have been performed.

\section{Conclusions}

Until December 2007, when results of the MENDS (Maximizing Efficacy of Targeted Sedation and Reducing Neurologic Dysfunction) trial were published, most of the data published on dexmedetomidine were from its use in surgical patients unique as a coadjuvant anesthetic [105]. Administered intravenously, dexmedetomidine has been used for sedation and anxiolysis in the intensive care unit and as other additional perioperative uses: premedication, to reduce emergence delirium and postoperative pain, and to attenuate the stress responses associated with surgery and anesthesia. But it will be necessary to explore the pharmacological mechanisms for the actions of these ( $\alpha$-)2-adrenergic receptor agonists in more detail. The incipient clinical use of dexmedetomidine can be ascribed to its recent introduction as anesthetic in human and veterinary practices. Since inflammation is normally a component of surgery-associated injuries, it would be valuable to have a safe and effective means of preventing inflammatory response to major surgery, especially to coronary artery bypass grafting, and its complications, with the beneficial actions of anesthetic drugs. We believe that dexmedetomidine can be considered a particularly promising agent. Other anesthetic approaches will be required to test the efficacy of dexmedetomidine as an anti-inflammatory agent and to further clarify both safety and efficacy to dexmedetomidine use in patients undergoing extremely invasive surgeries, such as cardiopulmonary bypass.

\section{Conflict of Interests}

The authors declare that there is no conflict of interests.

\section{Acknowledgments}

The authors would like to thank CAPES, CNPQ, INCT for Excitotoxicity and Neuroprotection, IBNET-FINEP, FINEP, and FAPERGS-PRONEX for financial support.

\section{References}

[1] M. Sander, C. von Heymann, V. von Dossow et al., "Increased interleukin-6 after cardiac surgery predicts infection," Anesthesia and Analgesia, vol. 102, no. 6, pp. 1623-1629, 2006.

[2] J. M. Murkin, "Panvascular inflammation and mechanisms of injury in perioperative CNS outcomes," Seminars in Cardiothoracic and Vascular Anesthesia, vol. 14, no. 3, pp. 190-195, 2010.

[3] M. E. Plomondon, J. C. Cleveland Jr., S. T. Ludwig et al., "Offpump coronary artery bypass is associated with improved riskadjusted outcomes," Annals of Thoracic Surgery, vol. 72, no. 1, pp. 114-119, 2001.

[4] S. Wan, J.-L. Leclerc, and J.-L. Vincent, "Inflammatory response to cardiopulmonary bypass: mechanisms involved and possible therapeutic strategies," Chest, vol. 112, no. 3, pp. 676-692, 1997.

[5] M. M. Elahi, J. S. Khan, and B. M. Matata, "Deleterious effects of cardiopulmonary bypass in coronary artery surgery and scientific interpretation of off-pump's logic," Acute Cardiac Care, vol. 8, no. 4, pp. 196-209, 2006. 
[6] B. M. Matata, A. W. Sosnowski, and M. Galiñanes, "Off-pump bypass graft operation significantly reduces oxidative stress and inflammation," Annals of Thoracic Surgery, vol. 69, no. 3, pp. 785-791, 2000.

[7] B. M. Matata and M. Galiñanes, "Cardiopulmonary bypass exacerbates oxidative stress but does not increase proinflammatory cytokine release in patients with diabetes compared with patients without diabetes: regulatory effects of exogenous nitric oxide," Journal of Thoracic and Cardiovascular Surgery, vol. 120, no. 1, pp. 1-11, 2000.

[8] E. P. Stover, L. C. Siegel, R. Parks et al., "Variability in transfusion practice for coronary artery bypass surgery persists despite national consensus guidelines: a 24-institution study," Anesthesiology, vol. 88, no. 2, pp. 327-333, 1998.

[9] S. C. Stamou, P. C. Hill, G. Dangas et al., "Stroke after coronary artery bypass: incidince, predictors, and clinical outcome," Stroke, vol. 32, no. 7, pp. 1508-1512, 2001.

[10] J. P. Mathew, R. Parks, J. S. Savino et al., "Atrial fibrillation following coronary artery bypass graft surgery: predictors, outcomes, and resource utilization. MultiCenter Study of Perioperative Ischemia Research Group," Journal of the American Medical Association, vol. 276, no. 4, pp. 300-306, 1996.

[11] E. A. Rose, "Off-pump coronary-artery bypass surgery," The New England Journal of Medicine, vol. 348, no. 5, pp. 379-380, 2003.

[12] R. Ascione, M. Caputo, and G. D. Angelini, "Off-pump coronary artery bypass grafting: not a flash in the pan," Annals of Thoracic Surgery, vol. 75, no. 1, pp. 306-313, 2003.

[13] J. E. Hall, T. D. Uhrich, J. A. Barney, S. R. Arain, and T. J. Ebert, "Sedative, amnestic, and analgesic properties of smalldose dexmedetomidine infusions," Anesthesia and Analgesia, vol. 90, no. 3, pp. 699-705, 2000.

[14] J. H. Gibbon Jr., "Application of a mechanical heart and lung apparatus to cardiac surgery," Minnesota medicine, vol. 37, no. 3, pp. 171-185, 1954.

[15] Y.-F. Chen, W.-C. Tsai, C.-C. Lin et al., "Effect of leukocyte depletion on endothelial cell activation and transendothelial migration of leukocytes during cardiopulmonary bypass," Annals of Thoracic Surgery, vol. 78, no. 2, pp. 634-642, 2004.

[16] T. Okamura, N. Ishibashi, D. Zurakowski, and R. A. Jonas, "Cardiopulmonary Bypass Increases Permeability of the BloodCerebrospinal Fluid Barrier," Annals of Thoracic Surgery, vol. 89, no. 1, pp. 187-194, 2010.

[17] O. J. Warren, A. J. Smith, C. Alexiou et al., “The inflammatory response to cardiopulmonary bypass: part 1-mechanisms of pathogenesis," Journal of Cardiothoracic and Vascular Anesthesia, vol. 23, no. 2, pp. 223-231, 2009.

[18] K. C. Wood, L. L. Hsu, and M. T. Gladwin, "Sickle cell disease vasculopathy: a state of nitric oxide resistance," Free Radical Biology and Medicine, vol. 44, no. 8, pp. 1506-1528, 2008.

[19] S. Kumar and U. Bandyopadhyay, "Free heme toxicity and its detoxification systems in human," Toxicology Letters, vol. 157, no. 3, pp. 175-188, 2005.

[20] D. J. Schaer, P. W. Buehler, A. I. Alayash, J. D. Belcher, and G. M. Vercellotti, "Hemolysis and free hemoglobin revisited: exploring hemoglobin and hemin scavengers as a novel class of therapeutic proteins," Blood, vol. 121, pp. 1276-1284, 2013.

[21] I. C. Vermeulen Windsant, S. J. Hanssen, W. A. Buurman, and M. J. Jacobs, "Cardiovascular surgery and organ damage: time to reconsider the role of hemolysis," Journal of Thoracic and Cardiovascular Surgery, vol. 142, no. 1, pp. 1-11, 2011.
[22] M. Haase, R. Bellomo, and A. Haase-Fielitz, "Novel biomarkers, oxidative stress, and the role of labile iron toxicity in cardiopulmonary bypass-associated acute kidney injury," Journal of the American College of Cardiology, vol. 55, no. 19, pp. 2024-2033, 2010.

[23] F. Farina, D. S. Davila, J. B. T. Rocha et al., "Metals, oxidative stress and neurodegeneration: a focus on iron, manganese and mercury," Neurochemistry International, vol. 62, no. 5, pp. 575594, 2012.

[24] M. Haase, A. Haase-Fielitz, and R. Bellomo, "Cardiopulmonary bypass, hemolysis, free iron, acute kidney injury and the impact of bicarbonate," Contributions to Nephrology, vol. 165, pp. 28-32, 2010.

[25] C. Ritter, M. E. Andrades, A. Reinke, S. Menna-Barreto, J. C. F. Moreira, and F. Dal-Pizzol, "Treatment with N-acetylcysteine plus deferoxamine protects rats against oxidative stress and improves survival in sepsis," Critical Care Medicine, vol. 32, no. 2, pp. 342-349, 2004.

[26] M. Vulcano, R. P. Meiss, and M. A. Isturiz, "Deferoxamine reduces tissue injury and lethality in LPS-treated mice," International Journal of Immunopharmacology, vol. 22, no. 8, pp. 635644, 2000.

[27] D. Vlahakos, N. Arkadopoulos, G. Kostopanagiotou et al., "Deferoxamine attenuates lipid peroxidation, blocks interleukin-6 production, ameliorates sepsis inflammatory response syndrome, and confers renoprotection after acute hepatic ischemia in pigs," Artificial Organs, vol. 36, no. 4, pp. 400-408, 2012.

[28] L. H. Edmunds, "Extracorporeal perfusion," in Cardiac Surgery in the Adult, L. H. Edmunds, Ed., pp. 255-294, McGraw-Hill, New York, NY, USA, 1997.

[29] M. Rossi, G. Sganga, M. Mazzone et al., "Cardiopulmonary bypass in man: role of the intestine in a self-limiting inflammatory response with demonstrable bacterial translocation," Annals of Thoracic Surgery, vol. 77, no. 2, pp. 612-618, 2004.

[30] B. Krishnadasam, J. Griscavage-Ennis, and G. S. Aldea, "Reperfusion injury during cardiopulmonary bypass," in Leukocyte Depletion in Cardiac Surgery and Cardiology, G. Matheis, A. Moritz, and M. Scholz, Eds., p. 54, Karger, Basel, Switzerland, 2002.

[31] N. B. Aydin, H. Gercekoglu, B. Aksu et al., "Endotoxemia in coronary artery bypass surgery: a comparison of the off-pump technique and conventional cardiopulmonary bypass," Journal of Thoracic and Cardiovascular Surgery, vol. 125, no. 4, pp. 843848, 2003.

[32] H. M. Oudemans-van Straaten, P. G. M. Jansen, F. J. Hoek et al., "Intestinal permeability, circulating endotoxin, and postoperative systemic responses in cardiac surgery patients," Journal of Cardiothoracic and Vascular Anesthesia, vol. 10, no. 2, pp. 187194, 1996.

[33] U. Koca, Ç. G. Olguner, B. U. Ergür et al., "The effects of dexmedetomidine on secondary acute lung and kidney injuries in the rat model of intra-abdominal sepsis," The Scientific World Journal, vol. 2013, Article ID 292687, 11 pages, 2013.

[34] H. A. Vohra, R. Whistance, A. Modi, and S. K. Ohri, “The inflammatory response to miniaturised extracorporeal circulation: a review of the literature," Mediators of Inflammation, vol. 2009, Article ID 707042, 7 pages, 2009.

[35] P. Menasché, “The inflammatory response to cardiopulmonary bypass and its impact on post-operative myocardial function," Current Opinion in Cardiology, vol. 10, pp. 597-604, 1995. 
[36] D. Journois, "Hemofiltration during cardiopulmonary bypass," Kidney International, vol. 53, no. 66, pp. S-174-S-177, 1998.

[37] G. Clermont, C. Vergely, S. Jazayeri et al., "Systemic free radical activation is a major event involved in myocardial oxidative stress related to cardiopulmonary bypass," Anesthesiology, vol. 96, no. 1, pp. 80-87, 2002.

[38] S. W. Davies, J. P. Duffy, D. G. Wickens et al., "Time-course of free radical activity during coronary artery operations with cardiopulmonary bypass," Journal of Thoracic and Cardiovascular Surgery, vol. 105, no. 6, pp. 979-987, 1993.

[39] P. E. Ballmer, W. H. Reinhart, P. Jordan, E. Buhler, U. K. Moser, and K. F. Gey, "Depletion of plasma vitamin C but not of vitamin E in response to cardiac operations," Journal of Thoracic and Cardiovascular Surgery, vol. 108, no. 2, pp. 311-320, 1994.

[40] H. J. Toivonen and M. Ahotupa, "Free radical reaction products and antioxidant capacity in arterial plasma during coronary artery bypass grafting," Journal of Thoracic and Cardiovascular Surgery, vol. 108, no. 1, pp. 140-147, 1994.

[41] A. Akila, B. D'souza, P. Vishwanath, and V. D'souza, “Oxidative injury and antioxidants in coronary artery bypass graft surgery: off-pump CABG significantly reduces oxidative stress," Clinica Chimica Acta, vol. 375, no. 1-2, pp. 147-152, 2007.

[42] J. Milei, P. Forcada, C. G. Fraga et al., "Relationship between oxidative stress, lipid peroxidation, and ultrastructural damage in patients with coronary artery disease undergoing cardioplegic arrest/reperfusion," Cardiovascular Research, vol. 73, no. 4, pp. 710-719, 2007.

[43] C. W. Hogue Jr., C. A. Palin, and J. E. Arrowsmith, "Cardiopulmonary bypass management and neurologic outcomes: an evidence-based appraisal of current practices," Anesthesia and Analgesia, vol. 103, no. 1, pp. 21-37, 2006.

[44] P. L. C. Smith, "The systemic inflammatory response to cardiopulmonary bypass and the brain," Perfusion, vol. 11, no. 3, pp. 196-199, 1996.

[45] J. M. Murkin, "Etiology and incidence of brain dysfunction after cardiac surgery," Journal of Cardiothoracic and Vascular Anesthesia, vol. 13, no. 4, pp. 12-17, 1999.

[46] F. de Lange, J. M. Dieleman, B. Jungwirth, and C. J. Kalkman, "Effects of cardiopulmonary bypass on neurocognitive performance and cytokine release in old and diabetic rats," British Journal of Anaesthesia, vol. 99, no. 2, pp. 177-183, 2007.

[47] S. Westaby, K. Saatvedt, S. White, T. Katsumata, W. van Oeveren, and P. W. Halligan, "Is there a relationship between cognitive dysfunction and systemic inflammatory response after cardiopulmonary bypass?" Annals of Thoracic Surgery, vol. 71, no. 2, pp. 667-672, 2001.

[48] A. Parolari, M. Camera, F. Alamanni et al., "Systemic inflammation after on-pump and off-pump coronary bypass surgery: a one-month follow-up," Annals of Thoracic Surgery, vol. 84, no. 3, pp. 823-828, 2007.

[49] C. Coimba, M. Drake, F. Boris-Moller et al., "Long-lasting neuroprotective effect of postischemic hypothermia and treatment with an antiimflammatory/antipyretic drug," Stroke, vol. 27, pp. 1578-1585, 1996.

[50] D. S. Warner, H. Sheng, and I. Batinić-Haberle, "Oxidants, antioxidants and the ischemic brain," Journal of Experimental Biology, vol. 207, no. 18, pp. 3221-3231, 2004.

[51] A. E. van Harten, T. W. L. Scheeren, and A. R. Absalom, "A review of postoperative cognitive dysfunction and neuroinflammation associated with cardiac surgery and anaesthesia," Anaesthesia, vol. 67, no. 3, pp. 280-293, 2012.
[52] P. Währborg, J. E. Booth, T. Clayton et al., "Neuropsychological outcome after percutaneous coronary intervention or coronary artery bypass grafting: results from the Stent or Surgery (SoS) trial," Circulation, vol. 110, no. 22, pp. 3411-3417, 2004.

[53] B. Ø. Jensen, L. S. Rasmussen, and D. A. Steinbrüchel, "Cognitive outcomes in elderly high-risk patients 1 year after off-pump versus on-pump coronary artery bypass grafting. A randomized trial," European Journal of Cardio-thoracic Surgery, vol. 34, no. 5, pp. 1016-1021, 2008.

[54] D. van Dijk, M. Spoor, R. Hijman et al., "Cognitive and cardiac outcomes 5 years after off-pump vs on-pump coronary artery bypass graft surgery," Journal of the American Medical Association, vol. 297, no. 7, pp. 701-708, 2007.

[55] M. F. Newman, J. P. Mathew, H. P. Grocott et al., "Central nervous system injury associated with cardiac surgery," The Lancet, vol. 368, no. 9536, pp. 694-703, 2006.

[56] C. S. Ernest, B. M. Murphy, M. U. C. Worcester et al., "Cognitive function in candidates for coronary artery bypass graft surgery," Annals of Thoracic Surgery, vol. 82, no. 3, pp. 812-818, 2006.

[57] O. A. Selnes, M. A. Grega, M. M. Bailey et al., "Cognition 6 years after surgical or medical therapy for coronary artery disease," Annals of Neurology, vol. 63, no. 5, pp. 581-590, 2008.

[58] D. van Dijk, K. G. M. Moons, H. M. Nathoe et al., "Cognitive outcomes five years after not undergoing coronary artery bypass graft surgery," Annals of Thoracic Surgery, vol. 85, no. 1, pp. 6064, 2008.

[59] O. A. Selnes, L. Pham, S. Zeger, and G. M. McKhann, "Defining cognitive change after CABG: decline versus normal variability," Annals of Thoracic Surgery, vol. 82, no. 2, pp. 388-390, 2006.

[60] D. van Dijk and C. J. Kalkman, "Why are cerebral microemboli not associated with cognitive decline?" Anesthesia and Analgesia, vol. 109, no. 4, pp. 1006-1008, 2009.

[61] B. Jungwirth, B. Eckel, M. Blobner, K. Kellermann, E. F. Kochs, and G. B. Mackensen, "The impact of cardiopulmonary bypass on systemic interleukin-6 release, cerebral nuclear factor-kappa B expression, and neurocognitive outcome in rats," Anesthesia and Analgesia, vol. 110, no. 2, pp. 312-320, 2010.

[62] B. S. Silbert, D. A. Scott, L. A. Evered, M. S. Lewis, and P. T. Maruff, "Preexisting cognitive impairment in patients scheduled for elective coronary artery bypass graft surgery," Anesthesia and Analgesia, vol. 104, no. 5, pp. 1023-1028, 2007.

[63] F. Winningham-Major, J. L. Staecker, S. W. Barger, S. Coats, and L. J. van Eldik, "Neurite extension and neuronal survival activities of recombinant $S 100 \beta$ proteins that differ in the content and position of cysteine residues," Journal of Cell Biology, vol. 109, no. 6, pp. 3063-3071, 1989.

[64] F. Tramontina, M. C. Leite, D. Gonçalves et al., "High glutamate decreases S100B secretion by a mechanism dependent on the glutamate transporter," Neurochemical Research, vol. 31, no. 6, pp. 815-820, 2006.

[65] R. Donato, G. Sorci, F. Riuzzi et al., "S100B’s double life: intracellular regulator and extracellular signal," Biochimica et Biophysica Acta, vol. 1793, no. 6, pp. 1008-1022, 2009.

[66] D. F. de Souza, K. Wartchow, F. Hansen et al., "Interleukin6-induced S100B secretion is inhibited by haloperidol and risperidone," Progress in Neuro-Psychopharmacology \& Biological Psychiatry, vol. 43, pp. 14-22, 2013.

[67] D. F. de Souza, M. C. Leite, A. Quincozes-Santos et al., "S100B secretion is stimulated by IL- $1 \beta$ in glial cultures and hippocampal slices of rats: likely involvement of MAPK pathway," Journal of Neuroimmunology, vol. 206, no. 1-2, pp. 52-57, 2009. 
[68] C. Beer, D. Blacker, M. Bynevelt, G. J. Hankey, and I. B. Puddey, "Systemic markers of inflammation are independently associated with $\mathrm{S} 100 \mathrm{~B}$ concentration: results of an observational study in subjects with acute ischaemic stroke," Journal of Neuroinflammation, vol. 7, article 71, 2010.

[69] A. Reichenberg, R. Yirmiya, A. Schuld et al., "Cytokineassociated emotional and cognitive disturbances in humans," Archives of General Psychiatry, vol. 58, no. 5, pp. 445-452, 2001.

[70] H. J. Huttunen, J. Kuja-Panula, G. Sorci, A. L. Agneletti, R. Donato, and H. Rauvala, "Coregulation of neurite outgrowth and cell survival by amphoterin and S100 proteins through receptor for advanced glycation end products (RAGE) activation," Journal of Biological Chemistry, vol. 275, no. 51, pp. 4009640105, 2000.

[71] A. Bierhaus, P. M. Humpert, M. Morcos et al., "Understanding RAGE, the receptor for advanced glycation end products," Journal of Molecular Medicine, vol. 83, no. 11, pp. 876-886, 2005.

[72] C. Adami, G. Sorci, E. Blasi, A. L. Agneletti, F. Bistoni, and R. Donato, "S100B expression in and effects on microglia," Glia, vol. 33, pp. 131-142, 2001.

[73] J. Hu, F. Castets, J. L. Guevara, and L. J. van Eldiki, "S100 $\beta$ stimulates inducible nitric oxide synthase activity and mRNA levels in rat cortical astrocytes," Journal of Biological Chemistry, vol. 271, no. 5, pp. 2543-2547, 1996.

[74] T. V. Petrova, J. Hu, and L. J. van Eldik, "Modulation of glial activation by astrocyte-derived protein S100B: differential responses of astrocyte and microglial cultures," Brain Research, vol. 853, no. 1, pp. 74-80, 2000.

[75] J. Hu, A. Ferreira, and L. J. van Eldik, "S100 $\beta$ induces neuronal cell death through nitric oxide release from astrocytes," Journal of Neurochemistry, vol. 69, no. 6, pp. 2294-2301, 1997.

[76] S. H. Kim, C. J. Smith, and L. J. van Eldik, "Importance of MAPK pathways for microglial pro-inflammatory cytokine IL$1 \beta$ production," Neurobiology of Aging, vol. 25, no. 4, pp. 431-439, 2004.

[77] S. Westaby, P. Johnsson, A. J. Parry et al., "Serum S100 protein: a potential marker for cerebral events during cardiopulmonary bypass," Annals of Thoracic Surgery, vol. 61, no. 1, pp. 88-92, 1996.

[78] S. Blomquist, P. Johnsson, C. Lührs et al., "The appearance of S100 protein in serum during and immediately after cardiopulmonary bypass surgery: a possible marker for cerebral injury," Journal of Cardiothoracic and Vascular Anesthesia, vol. 11, no. 6, pp. 699-703, 1997.

[79] D. Barbut, F. S. Yao, D. N. Hager, P. Kavanaugh, R. R. Trifiletti, and J. P. Gold, "Comparison of transcranial Doppler ultrasonography and transesophageal echocardiography to monitor emboli during coronary artery bypass surgery," Stroke, vol. 27, no. 1, pp. 87-90, 1996.

[80] H. Jönsson, P. Johnsson, C. Alling, S. Westaby, and S. Blomquist, "Significance of serum S100 release after coronary artery bypass grafting," Annals of Thoracic Surgery, vol. 65, no. 6, pp. 1639$1644,1998$.

[81] H. P. Grocott, N. D. Croughwell, D. W. Amory et al., "Cerebral emboli and serum S100 $\beta$ during cardiac operations," Annals of Thoracic Surgery, vol. 65, no. 6, pp. 1645-1650, 1998.

[82] A. Jonsson, "As compared to neuron-specific enolase, S100B protein correlate more specific to the stroke volume and clinical outcome in ischemic stroke," Kaka-Orinska, 2010.
[83] B. C. van Munster, J. C. Korevaar, A. H. Zwinderman, M. Levi, W. J. Wiersinga, and S. E. De Rooij, "Time-course of cytokines during delirium in elderly patients with hip fractures," Journal of the American Geriatrics Society, vol. 56, no. 9, pp. 1704-1709, 2008.

[84] H. Worthmann, A. B. Tryc, A. Goldbecker et al., “The temporal profile of inflammatory markers and mediators in blood after acute ischemic stroke differs depending on stroke outcome," Cerebrovascular Diseases, vol. 30, no. 1, pp. 85-92, 2010.

[85] J. W. W. Thomason, A. Shintani, J. F. Peterson, B. T. Pun, J. C. Jackson, and E. W. Ely, "Intensive care unit delirium is an independent predictor of longer hospital stay: a prospective analysis of 261 non-ventilated patients," Critical Care, vol. 9, no. 4, pp. R375-381, 2005.

[86] P. Pandharipande, B. A. Cotton, A. Shintani et al., "Prevalence and risk factors for development of delirium in surgical and trauma intensive care unit patients," The Journal of trauma, vol. 65, no. 1, pp. 34-41, 2008.

[87] M. Lundström, A. Edlund, G. Bucht, S. Karlsson, and Y. Gustafson, "Dementia after delirium in patients with femoral neck fractures," Journal of the American Geriatrics Society, vol. 51, no. 7, pp. 1002-1006, 2003.

[88] V. H. Perry, "The influence of systemic inflammation on inflammation in the brain: implications for chronic neurodegenerative disease," Brain, Behavior, and Immunity, vol. 18, no. 5, pp. 407413, 2004.

[89] M. Herrmann, A. D. Ebert, I. Galazky, M. T. Wunderlich, W. S. Kunz, and C. Huth, "Neurobehavioral outcome prediction after cardiac surgery: role of neurobiochemical markers of damage to neuronal and glial brain tissue," Stroke, vol. 31, no. 3, pp. 645$650,2000$.

[90] Z. P. Khan, C. N. Ferguson, and R. M. Jones, "Alpha-2 and imidazoline receptor agonists. Their pharmacology and therapeutic role," Anaesthesia, vol. 54, no. 2, pp. 146-165, 1999.

[91] D. S. Carollo, B. D. Nossaman, and U. Ramadhyani, "Dexmedetomidine: a review of clinical applications," Current Opinion in Anaesthesiology, vol. 21, no. 4, pp. 457-461, 2008.

[92] J. C. Eisenach, M. de Kock, and W. Klimscha, " $\alpha 2$-Adrenergic agonists for regional anesthesia: a clinical review of clonidine (1984-1995)," Anesthesiology, vol. 85, no. 3, pp. 655-674, 1996.

[93] M. Maze and W. Tranquilli, "Alpha-2 adrenoceptor agonists: defining the role in clinical anesthesia," Anesthesiology, vol. 74, no. 3, pp. 581-605, 1991.

[94] S. Fürst, "Transmitters involved in antinociception in the spinal cord," Brain Research Bulletin, vol. 48, no. 2, pp. 129-141, 1999.

[95] H. M. Loick, C. Schmidt, H. van Aken et al., "High thoracic epidural anesthesia, but not clonidine, attenuates the perioperative stress response via sympatholysis and reduces the release of troponin $\mathrm{T}$ in patients undergoing coronary artery bypass grafting," Anesthesia and Analgesia, vol. 88, no. 4, pp. 701-709, 1999.

[96] A. W. Wallace, D. Galindez, A. Salahieh et al., "Effect of clonidine on cardiovascular morbidity and mortality after noncardiac surgery," Anesthesiology, vol. 101, no. 2, pp. 284-293, 2004.

[97] R. D. Stevens, H. Burri, and M. R. Tramèr, "Efficacy of clonidine for prevention of perioperative myocardial ischemia: a critical appraisal and meta-analysis of the literature," Anesthesia \& Analgesia, vol. 97, pp. 623-633, 2003. 
[98] K. Nishina, K. Mikawa, T. Uesugi et al., "Efficacy of clonidine for prevention of perioperative myocardial ischemia: a critical appraisal and meta-analysis of the literature," Anesthesiology, vol. 96, no. 2, pp. 323-329, 2002.

[99] V. von Dossow, N. Baehr, M. Moshirzadeh et al., "Clonidine attenuated early proinflammatory response in T-cell subsets after cardiac surgery," Anesthesia and Analgesia, vol. 103, no. 4, pp. 809-814, 2006.

[100] J. E. Ellis, S. Pedlow, and J. Bains, "Premedication with clonidine does not attenuate suppression of certain lymphocyte subsets after surgery," Anesthesia and Analgesia, vol. 87, no. 6, pp. 1426$1430,1998$.

[101] T. Dorman, K. Clarkson, B. A. Rosenfeld, C. Shanholtz, P. A. Lipsett, and M. J. Breslow, "Effects of clonidine on prolonged postoperative sympathetic response," Critical Care Medicine, vol. 25, no. 7, pp. 1147-1152, 1997.

[102] P. J. Kulka, M. Tryba, and M. Zenz, "Dose-response effects of intravenous clonidine on stress response during induction of anesthesia in coronary artery bypass graft patients," Anesthesia and Analgesia, vol. 80, no. 2, pp. 263-268, 1995.

[103] N. D. Nader, T. A. Ignatowski, C. J. Kurek, P. R. Knight, and R. N. Spengler, "Clonidine suppresses plasma and cerebrospinal fluid concentrations of TNF- $\alpha$ during the perioperative period," Anesthesia and Analgesia, vol. 93, no. 2, pp. 363-369, 2001.

[104] J. Persec, Z. Persec, and I. Husedzinovic, "Postoperative pain and systemic inflammatory stress response after preoperative analgesia with clonidine or levobupivacaine: a randomized controlled trial," Wiener Klinische Wochenschrift, vol. 121, no. 1718, pp. 558-563, 2009.

[105] A. T. Guerlach and J. F. Dasta, "Dexmedetomidine: an updated review," Annals of Pharmacotherapy, vol. 41, pp. 245-252, 2007.

[106] D. Ma, N. Rajakumaraswamy, and M. Maze, " $\alpha 2$-adrenoceptor agonists: shedding light on neuroprotection?" British Medical Bulletin, vol. 71, pp. 77-92, 2005.

[107] V. Fagerholm, M. Scheinin, and M. Haaparanta, " $\alpha 2 \mathrm{~A}$ Adrenoceptor antagonism increases insulin secretion and synergistically augments the insulinotropic effect of glibenclamide in mice," British Journal of Pharmacology, vol. 154, no. 6, pp. 1287-1296, 2008.

[108] K. Takada, D. J. Clark, M. F. Davies et al., "Meperidine exerts agonist activity at the $\alpha 2 \mathrm{~B}$-adrenoceptor subtype," Anesthesiology, vol. 96, no. 6, pp. 1420-1426, 2002.

[109] V. Fagerholm, J. Rokka, L. Nyman et al., "Autoradiographic characterization of $\alpha 2 \mathrm{C}$-adrenoceptors in the human striatum," Synapse, vol. 62, no. 7, pp. 508-515, 2008.

[110] E. Moura, J. Afonso, L. Hein, and M. A. Vieira-Coelho, " $\alpha 2-$ adrenoceptor subtypes involved in the regulation of catecholamine release from the adrenal medulla of mice," British Journal of Pharmacology, vol. 149, no. 8, pp. 1049-1058, 2006.

[111] I. Takamatsu, A. Iwase, M. Ozaki, T. Kazama, K. Wada, and M. Sekiguchi, "Dexmedetomidine reduces long-term potentiation in mouse hippocampus," Anesthesiology, vol. 108, no. 1, pp. 94$102,2008$.

[112] R. M. Venn, M. D. Karol, and R. M. Grounds, "Pharmacokinetics of dexmedetomidine infusions for sedation of postoperative patients requiring intensive care," British Journal of Anaesthesia, vol. 88 , no. 5, pp. 669-675, 2002.

[113] A. M. de Wolf, R. J. Fragen, M. J. Avram, P. C. Fitzgerald, and F. Rahimi-Danesh, "The pharmacokinetics of dexmedetomidine in volunteers with severe renal impairment," Anesthesia and Analgesia, vol. 93, no. 5, pp. 1205-1209, 2001.
[114] P. Talke, C. A. Richardson, M. Scheinin, and D. M. Fisher, "Postoperative pharmacokinetics and sympatholytic effects of dexmedetomidine," Anesthesia and Analgesia, vol. 85, no. 5, pp. 1136-1142, 1997.

[115] A. Kallio, M. Scheinin, M. Koulu et al., "Effects of dexmedetomidine, a selective $\alpha 2$-adrenoceptor agonist, on hemodynamic control mechanisms," Clinical Pharmacology and Therapeutics, vol. 46, no. 1, pp. 33-42, 1989.

[116] T. J. Ebert, J. E. Hall, J. A. Barney, T. D. Uhrich, and M. D. Colinco, "The effects of increasing plasma concentrations of dexmedetomidine in humans," Anesthesiology, vol. 93, no. 2, pp. 382-394, 2000.

[117] V. S. B. Jorden, R. M. Pousman, M. M. Sanford, P. A. J. Thorborg, and M. P. Hutchens, "Dexmedetomidine overdose in the perioperative setting," Annals of Pharmacotherapy, vol. 38, no. 5, pp. 803-807, 2004.

[118] M. A. E. Ramsay and D. L. Luterman, "Dexmedetomidine as a total intravenous anesthetic agent," Anesthesiology, vol. 101, no. 3, pp. 787-790, 2004.

[119] J. Sleigh, "All hands on dex," Anaesthesia, vol. 67, pp. 1193-1197, 2012.

[120] M. Aho, O. Erkola, A. Kallio, H. Scheinin, and K. Korttila, "Dexmedetomidine infusion for maintenance of anesthesia in patients undergoing abdominal hysterectomy," Anesthesia and Analgesia, vol. 75, no. 6, pp. 940-946, 1992.

[121] H. Ishii, T. Kohno, T. Yamakura, M. Ikoma, and H. Baba, "Action of dexmedetomidine on the substantia gelatinosa neurons of the rat spinal cord," European Journal of Neuroscience, vol. 27, no. 12, pp. 3182-3190, 2008.

[122] L. E. Nelson, T. You, M. Maze, and N. P. Franks, "Evidence that the mechanism of hypnotic action in dexmedetomidine and muscimol-induced anesthesia converges on the endogenous sleep pathway," Anesthesiology, vol. 95, p. A1368, 2001.

[123] R. R. Al-Metwalli, H. A. Mowafi, S. A. Ismail et al., "Effect of intra-articular dexmedetomidine on postoperative analgesia after arthroscopic knee surgery," British Journal of Anaesthesia, vol. 101, no. 3, pp. 395-399, 2008.

[124] T. Yoshitomi, A. Kohjitani, S. Maeda, H. Higuchi, M. Shimada, and T. Miyawaki, "Dexmedetomidine enhances the local anesthetic action of lidocaine via an $\alpha$-2a adrenoceptor," Anesthesia and Analgesia, vol. 107, no. 1, pp. 96-101, 2008.

[125] A. Turkmen, A. Altan, N. Turgut, S. Vatansever, and S. Gokkaya, "The correlation between the richmond agitation-sedation scale and bispectral index during dexmedetomidine sedation," European Journal of Anaesthesiology, vol. 23, no. 4, pp. 300-304, 2006.

[126] R. Aantaa, "Assessment of the sedative effects of dexmedetomidine, an $\alpha 2$-adrenoceptor agonist, with analysis of saccadic eye movements," Pharmacology and Toxicology, vol. 68, no. 5, pp. 394-398, 1991.

[127] W. J. Elias, M. E. Durieux, D. Huss, and R. C. Frysinger, "Dexmedetomidine and arousal affect subthalamic neurons," Movement Disorders, vol. 23, no. 9, pp. 1317-1320, 2008.

[128] Y.-W. Hsu, L. I. Cortinez, K. M. Robertson et al., "Dexmedetomidine pharmacodynamics: part I-crossover comparison of the respiratory effects of dexmedetomidine and remifentanil in healthy volunteers," Anesthesiology, vol. 101, no. 5, pp. $1066-$ 1076, 2004.

[129] J. T. Coull, M. E. P. Jones, T. D. Egan, C. D. Frith, and M. Maze, "Attentional effects of noradrenaline vary with arousal 
level: selective activation of thalamic pulvinar in humans," NeuroImage, vol. 22, no. 1, pp. 315-322, 2004.

[130] E. Deutsch and J. D. Tobias, "Hemodynamic and respiratory changes following dexmedetomidine administration during general anesthesia: sevoflurane vs desflurane," Paediatric Anaesthesia, vol. 17, no. 5, pp. 438-444, 2007.

[131] A. Koroglu, H. Teksan, O. Sagir, A. Yucel, H. I. Toprak, and O. M. Ersoy, "A comparison of the sedative, hemodynamic, and respiratory effects of dexmedetomidine and propofol in children undergoing magnetic resonance imaging," Anesthesia and Analgesia, vol. 103, no. 1, pp. 63-67, 2006.

[132] P. A. Arpino, K. Kalafatas, and B. T. Thompson, "Feasibility of dexmedetomidine in facilitating extubation in the intensive care unit," Journal of Clinical Pharmacy and Therapeutics, vol. 33, no. 1, pp. 25-30, 2008.

[133] T. B. Corcoran, A. Engel, H. Sakamoto, A. O’Shea, S. O'Callaghan-Enright, and G. D. Shorten, "The effects of propofol on neutrophil function, lipid peroxidation and inflammatory response during elective coronary artery bypass grafting in patients with impaired ventricular function," British Journal of Anaesthesia, vol. 97, no. 6, pp. 825-831, 2006.

[134] M. Arslan, F. M. Çomu, A. Kuçuk, L. Ozturk, and F. Yaylak, "Dexmedetomidine protects against lipid peroxidation and erythrocyte deformability alterations in experimental hepatic ischemia reperfusion injury," Libyan Journal of Medicine, vol. 7, article 18185, 2012.

[135] J. B. T. Rocha, N. M. Heinzmann Bulow, E. F. M. Correa, C. Scholze, C. W. Nogueira, and N. B. Barbosa, "Dexmedetomidine protects blood $\gamma$-aminolevulinate dehydratase from inactivation caused by hyperoxygenation in total intravenous anesthesia," Human and Experimental Toxicology, vol. 30, no. 4, pp. 289-295, 2011.

[136] R. H. Straub, M. Herrmann, G. Berkmiller et al., "Neuronal regulation of interleukin 6 secretion in murine spleen: adrenergic and opioidergic control," Journal of Neurochemistry, vol. 68, no. 4, pp. 1633-1639, 1997.

[137] J. Szelényi, J. P. Kiss, and E. S. Vizi, “Differential involvement of sympathetic nervous system and immune system in the modulation of TNF- $\alpha$ production by $\alpha 2$ - and $\beta$-adrenoceptors in mice," Journal of Neuroimmunology, vol. 103, no. 1, pp. 34-40, 2000.

[138] T. Taniguchi, Y. Kidani, H. Kanakura, Y. Takemoto, and K. Yamamoto, "Effects of dexmedetomidine on mortality rate and inflammatory responses to endotoxin-induced shock in rats," Critical Care Medicine, vol. 32, no. 6, pp. 1322-1326, 2004.

[139] S. Hofer, J. Steppan, T. Wagner et al., "Central sympatholytics prolong survival in experimental sepsis," Critical Care, vol. 13, no. 1, article R11, 2009.

[140] M. Can, S. Gul, S. Bektas, V. Hanci, and S. Acikgoz, "Effects of dexmedetomidine or methylprednisolone on inflammatory responses in spinal cord injury," Acta Anaesthesiologica Scandinavica, vol. 53, no. 8, pp. 1068-1072, 2009.

[141] M. Maze, R. Virtanen, D. Daunt, S. J. M. Banks, E. P. Stover, and D. Feldman, "Effects of dexmedetomidine, a novel imidazole sedative-anesthetic agent, on adrenal steroidogenesis: in vivo and in vitro studies," Anesthesia and Analgesia, vol. 73, no. 2, pp. 204-208, 1991.

[142] R. M. Venn, A. Bryant, G. M. Hall, and R. M. Grounds, "Effects of dexmedetomidine on adrenocortical function, and the cardiovascular, endocrine and inflammatory responses in post-operative patients needing sedation in the intensive care unit," British Journal of Anaesthesia, vol. 86, no. 5, pp. 650-656, 2001.

[143] N. M. H. Bulow, N. B. V. Barbosa, and J. B. T. Rocha, "Opioid consumption in total intravenous anesthesia is reduced with dexmedetomidine: a comparative study with remifentanil in gynecologic videolaparoscopic surgery," Journal of Clinical Anesthesia, vol. 19, no. 4, pp. 280-285, 2007.

[144] P. P. Pandharipande, B. T. Pun, D. L. Herr et al., "Effect of sedation with dexmedetomidine vs lorazepam on acute brain dysfunction in mechanically ventilated patients: the MENDS randomized controlled trial," Journal of the American Medical Association, vol. 298, no. 22, pp. 2644-2653, 2007.

[145] A. T. Gerlach, C. V. Murphy, and J. F. Dasta, "An updated focused review of dexmedetomidine in adults," Annals of Pharmacotherapy, vol. 43, no. 12, pp. 2064-2074, 2009.

[146] S. Sulaiman, R. B. Karthekeyan, M. Vakamudi, A. S. Sundar, H. Ravullapalli, and R. Gandham, "The effects of dexmedetomidine on attenuation of stress response to endotracheal intubation in patients undergoing elective off-pump coronary artery bypass grafting," Annals of Cardiac Anaesthesia, vol. 15, no. 1, pp. 39-43, 2012.

[147] B. Scheinin, L. Lindgren, T. Randell, H. Scheinin, and M. Scheinin, "Dexmedetomidine attenuates sympathoadrenal responses to tracheal intubation and reduces the need for thiopentone and peroperative fentanyl," British Journal of Anaesthesia, vol. 68, no. 2, pp. 126-131, 1992.

[148] S. Sukegawa, M. Inoue, H. Higuchi, Y. Tomoyasu, S. Maeda, and T. Miyawaki, "Locally injected dexmedetomidine inhibits carrageenin-induced inflammatory reactions in injected region," in Proceedings of the American Society of Anesthesiologists Annual Meeting, 2011, A1590.

[149] Y.-C. Lai, P.-S. Tsai, and C.-J. Huang, "Effects of dexmedetomidine on regulating endotoxin-induced up-regulation of inflammatory molecules in murine macrophages," Journal of Surgical Research, vol. 154, no. 2, pp. 212-219, 2009.

[150] H. Yagmurdur, N. Ozcan, F. Dokumaci, K. Kilinc, F. Yilmaz, and H. Basar, "Dexmedetomidine reduces the ischemia-reperfusion injury markers during upper extremity surgery with tourniquet," Journal of Hand Surgery, vol. 33, no. 6, pp. 941-947, 2008.

[151] A. Bekker, M. Haile, R. Kline et al., "The effect of intraoperative infusion of dexmedetomidine on the quality of recovery after major spinal surgery," Journal of Neurosurgical Anesthesiology, vol. 25, no. 1, pp. 16-24, 2012.

[152] J. Gu, J. Chen, P. Xia, G. Tao, H. Zhao, and D. Ma, "Dexmedetomidine attenuates remote lung injury induced by renal ischemia-reperfusion in mice," Acta Anaesthesiologica Scandinavica, vol. 55, no. 10, pp. 1272-1278, 2011.

[153] X. Wu, X. Song, N. Li, L. Zhan, Q. Meng, and Z. Xia, "Protective effects of dexmedetomidine on blunt chest trauma-induced pulmonary contusion in rats," Journal of Trauma and Acute Care Surgery, vol. 74, pp. 524-530, 2013.

[154] S.-H. Kang, Y.-S. Kim, T.-H. Hong et al., "Effects of dexmedetomidine on inflammatory responses in patients undergoing laparoscopic cholecystectomy," Acta Anaesthesiologica Scandinavica, vol. 57, pp. 480-487, 2013.

[155] M. Tasdogan, D. Memis, N. Sut, and M. Yuksel, "Results of a pilot study on the effects of propofol and dexmedetomidine on inflammatory responses and intraabdominal pressure in severe sepsis," Journal of Clinical Anesthesia, vol. 21, no. 6, pp. 394-400, 2009. 
[156] R. D. Sanders, D. Ma, and M. Maze, "Anaesthesia induced neuroprotection," Best Practice and Research, vol. 19, no. 3, pp. 461-474, 2005.

[157] E. L. Janke and S. Samra, "Dexmedetomidine and neuroprotection," Seminars in Anesthesia, Perioperative Medicine and Pain, vol. 25, no. 2, pp. 71-76, 2006.

[158] M. F. Newman, "Open heart surgery and cognitive decline," Cleveland Clinic journal of medicine, vol. 74, pp. S52-S55, 2007.

[159] N. Stroobant, G. van Nooten, D. de Bacquer, Y. van Belleghem, and G. Vingerhoets, "Neuropsychological functioning 3-5 years after coronary artery bypass grafting: does the pump make a difference?" European Journal of Cardio-thoracic Surgery, vol. 34, no. 2, pp. 396-401, 2008.

[160] H. P. Grocott, "Genetic influences on cerebral outcome after cardiac surgery," Seminars in Cardiothoracic and Vascular Anesthesia, vol. 10, no. 4, pp. 291-296, 2006.

[161] K. M. Taylor, "Central nervous system effects of cardiopulmonary bypass," Annals of Thoracic Surgery, vol. 66, no. 5, pp. S20-S24, 1998.

[162] C. W. Hogue Jr., T. Hershey, D. Dixon et al., "Preexisting cognitive impairment in women before cardiac surgery and its relationship with C-reactive protein concentrations," Anesthesia and Analgesia, vol. 102, no. 6, pp. 1602-1608, 2006.

[163] P. M. Ho, D. B. Arciniegas, J. Grigsby et al., "Predictors of cognitive decline following coronary artery bypass graft surgery," Annals of Thoracic Surgery, vol. 77, no. 2, pp. 597-603, 2004.

[164] C. G. Koch, L. Li, M. Shishehbor et al., "Socioeconomic status and comorbidity as predictors of preoperative quality of life in cardiac surgery," Journal of Thoracic and Cardiovascular Surgery, vol. 136, no. 3, pp. 665-672, 2008.

[165] N. Stroobant and G. Vingerhoets, "Depression, anxiety, and neuropsychological performance in coronary artery bypass graft patients: a follow-up study," Psychosomatics, vol. 49, no. 4, pp. 326-331, 2008.

[166] R. Ille, T. Lahousen, S. Schweiger, P. Hofmann, and H.-P. Kapfhammer, "Influence of patient-related and surgery-related risk factors on cognitive performance, emotional state, and convalescence after cardiac surgery," Cardiovascular Revascularization Medicine, vol. 8, no. 3, pp. 166-169, 2007.

[167] N. A. Nussmeier and B. E. Searles, "Inflammatory brain injury after cardiopulmonary bypass: is it real?" Anesthesia and Analgesia, vol. 110, no. 2, pp. 288-290, 2010.

[168] S. Singh, P. Kapoor, U. Chowdhury, and U. Kiran, "Comparison of S100 levels, and their correlation with hemodynamic indices in patients undergoing coronary artery bypass grafting with three different anesthetic techniques," Annals of Cardiac Anaesthesia, vol. 14, no. 3, pp. 197-202, 2011.

[169] A. Kleindienst, F. Hesse, M. R. Bullock, and M. Buchfelder, "The neurotrophic protein S100B: value as a marker of brain damage and possible therapeutic implications," Progress in Brain Research, vol. 161, pp. 317-325, 2007.

[170] R. R. Riker, Y. Shehabi, P. M. Bokesch et al., "Dexmedetomidine vs midazolam for sedation of critically Ill patients A randomized trial," Journal of the American Medical Association, vol. 301, no. 5, pp. 489-499, 2009.

[171] J. R. Maldonado, A. Wysong, P. J. A. van der Starre, T. Block, C. Miller, and B. A. Reitz, "Dexmedetomidine and the reduction of postoperative delirium after cardiac surgery," Psychosomatics, vol. 50, no. 3, pp. 206-217, 2009.
[172] E. Ruokonen, I. Parviainen, S. M. Jakob et al., "Dexmedetomidine versus propofol/midazolam for long-term sedation during mechanical ventilation," Intensive Care Medicine, vol. 35, no. 2, pp. 282-290, 2009.

[173] W. Mayo, V. Lemaire, J. Malaterre et al., "Pregnenolone sulfate enhances neurogenesis and PSA-NCAM in young and aged hippocampus," Neurobiology of Aging, vol. 26, no. 1, pp. 103-114, 2005.

[174] E. A. Keller, A. Zamparini, L. N. Borodinsky, M. C. Gravielle, and M. L. Fiszman, "Role of allopregnanolone on cerebellar granule cells neurogenesis," Developmental Brain Research, vol. 153, no. 1, pp. 13-17, 2004.

[175] C. Correa-Sales, B. C. Rabin, and M. Maze, "A hypnotic response to dexmedetomidine, an $\alpha 2$ agonist, is mediated in the locus coeruleus in rats," Anesthesiology, vol. 76, no. 6, pp. 948952, 1992

[176] V. A. Kulkarni, S. Jha, and V. A. Vaidya, "Depletion of norepinephrine decreases the proliferation, but does not influence the survival and differentiation, of granule cell progenitors in the adult rat hippocampus," European Journal of Neuroscience, vol. 16, no. 10, pp. 2008-2012, 2002.

[177] P. Mohapel, G. Leanza, M. Kokaia, and O. Lindvall, "Forebrain acetylcholine regulates adult hippocampal neurogenesis and learning," Neurobiology of Aging, vol. 26, no. 6, pp. 939-946, 2005.

[178] A. Tung, S. Herrera, C. A. Fornal, and B. L. Jacobs, "The effect of prolonged anesthesia with isoflurane, propofol, dexmedetomidine, or ketamine on neural cell proliferation in the adult rat," Anesthesia and Analgesia, vol. 106, no. 6, pp. 1772-1777, 2008.

[179] W. E. Hoffman, E. Kochs, C. Werner, C. Thomas, and R. F. Albrecht, "Dexmedetomidine improves neurologic outcome from incomplete ischemia in the rat. Reversal by the $\alpha 2$ adrenergic antagonist atipamezole," Anesthesiology, vol. 75, no. 2, pp. 328-332, 1991.

[180] W. E. Hoffman, V. L. Baughman, and R. F. Albrecht, "Interaction of catecholamines and nitrous oxide ventilation during incomplete brain ischemia in rats," Anesthesia and Analgesia, vol. 77, no. 5, pp. 908-912, 1993.

[181] C. Maier, G. K. Steinberg, G. H. Sun, G. T. Zhi, and M. Maze, "Neuroprotection by the $\alpha 2$-adrenoreceptor agonist dexmedetomidine in a focal model of cerebral ischemia," Anesthesiology, vol. 79, no. 2, pp. 306-312, 1993.

[182] J. Kuhmonen, J. Pokorný, R. Miettinen et al., "Neuroprotective effects of dexmedetomidine in the gerbil hippocampus after transient global ischemia," Anesthesiology, vol. 87, no. 2, pp. 371$377,1997$.

[183] V. Laudenbach, J. Mantz, H. Lagercrantz, J.-M. Desmonts, P. Evrard, and P. Gressens, "Effects of $\alpha 2$-adrenoceptor agonists on perinatal excitotoxic brain injury: comparison of clonidine and dexmedetomidine," Anesthesiology, vol. 96, no. 1, pp. 134141,2002

[184] L. Peng, A. C. H. Yu, K. Y. Fung, V. Prévot, and L. Hertz, “ $\alpha$ adrenergic stimulation of ERK phosphorylation in astrocytes is $\alpha 2$-specific and may be mediated by transactivation," Brain Research, vol. 978, no. 1-2, pp. 65-71, 2003.

[185] B. Li, T. Du, H. Li et al., "Signalling pathways for transactivation by dexmedetomidine of epidermal growth factor receptors in astrocytes and its paracrine effect on neurons," British Journal of Pharmacology, vol. 154, no. 1, pp. 191-203, 2008.

[186] L. Hertz, D. Lovatt, S. A. Goldman, and M. Nedergaard, "Adrenoceptors in brain: cellular gene expression and effects 
on astrocytic metabolism and [Ca2+]i," Neurochemistry International, vol. 57, no. 4, pp. 411-420, 2010.

[187] L. Peng, T. Du, J. Xu et al., "Adrenergic and V1-ergic agonists/antagonists affecting recovery from Brain Trauma in the Lund project Act on astrocytes," Current Signal Transduction Therapy, vol. 7, pp. 43-55, 2012.

[188] L. Liu, F. Ji, J. Liang, H. He, Y. Fu, and M. Cao, "Inhibition by dexmedetomidine of the activation of spinal dorsal horn glias and the intracellular ERK signaling pathway induced by nerve injury," Brain Research, vol. 1427, pp. 1-9, 2012.

[189] B. Xu, W. S. Zhang, J. L. Yang et al., "Evidence for suppression of spinal glial activation by dexmedetomidine in a rat model of monoarthritis.," Clinical and Experimental Pharmacology and Physiology, vol. 37, pp. 158-166, 2010.

[190] C. Chrysostomou and C. G. Schmitt, "Dexmedetomidine: sedation, analgesia and beyond," Expert Opinion on Drug Metabolism and Toxicology, vol. 4, no. 5, pp. 619-627, 2008.

[191] M. Schoeler, P. D. Loetscher, R. Rossaint et al., "Dexmedetomidine is neuroprotective in an in vitro model for traumatic brain injury," BMC Neurology, vol. 12, p. 20, 2012.

[192] M. Zhang, X. Shan, L. Gu, L. Hertz, and L. Peng, "Dexmedetomidine causes neuroprotection via astrocytic $\alpha_{2}$-adrenergic receptor stimulation and HB-EGF release," Journal of Anesthesiology \& Clinical Science, 2013.

[193] E. D. Hall, R. A. Vaishnav, and A. G. Mustafa, "Antioxidant Therapies for Traumatic Brain Injury," Neurotherapeutics, vol. 7, no. 1, pp. 51-61, 2010.

[194] P. S. Eriksson, E. Perfilieva, T. Björk-Eriksson et al., "Neurogenesis in the adult human hippocampus," Nature Medicine, vol. 4, no. 11, pp. 1313-1317, 1998.

[195] T. J. Shors, G. Miesegaes, A. Beylin, M. Zhao, T. Rydel, and E. Gould, "Neurogenesis in the adult is involved in the formation of trace memories," Nature, vol. 410, pp. 372-376, 2001.

[196] B. Leuner, E. Gould, and T. J. Shors, "Is there a link between adult neurogenesis and learning?” Hippocampus, vol. 16, no. 3, pp. 216-224, 2006.

[197] L. Henriksen, E. Hjelms, and T. Lindeburgh, "Brain hyperperfusion during cardiac operations. Cerebral blood flow measured in man by intra-arterial injection of xenon 133: evidence suggestive of intraoperative microembolism," Journal of Thoracic and Cardiovascular Surgery, vol. 86, no. 2, pp. 202-208, 1983.

[198] A. V. Govier, J. G. Reves, and R. D. McKay, "Factors and their influence on regional cerebral blood flow during nonpulsatile cardiopulmonary bypass," Annals of Thoracic Surgery, vol. 38, no. 6, pp. 592-600, 1984.

[199] J. M. Murkin, J. K. Farrar, W. A. Tweed, F. N. McKenzie, and G. Guiraudon, "Cerebral autoregulation and flow/metabolism coupling during cardiopulmonary bypass: the influence of PaCO2," Anesthesia and Analgesia, vol. 66, no. 9, pp. 825-832, 1987.

[200] Y. M. Ganushchak, E. J. Fransen, C. Visser, D. S. de Jong, and J. G. Maessen, "Neurological complications after coronary artery bypass grafting related to the performance of cardiopulmonary bypass," Chest, vol. 125, no. 6, pp. 2196-2205, 2004.

[201] W. E. Hoffman, E. Kochs, C. Werner, C. Thomas, and R. F. Albrecht, "Dexmedetomidine improves neurologic outcome from incomplete ischemia in the rat. Reversal by the $\alpha 2$ adrenergic antagonist atipamezole," Anesthesiology, vol. 75, no. 2, pp. 328-332, 1991.
[202] S. Dahmani, D. Rouelle, P. Gressens, and J. Mantz, "Characterization of the postconditioning effect of dexmedetomidine in mouse organotypic hippocampal slice cultures exposed to oxygen and glucose deprivation," Anesthesiology, vol. 112, no. 2, pp. 373-383, 2010.

[203] K. Engelhard, C. Werner, E. Eberspächer et al., "The effect of the $\alpha 2$-agonist dexmedetomidine and the $\mathrm{N}$-methyl-D-aspartate antagonist $\mathrm{S}(+)$-ketamine on the expression of apoptosisregulating proteins after incomplete cerebral ischemia and reperfusion in rats," Anesthesia and Analgesia, vol. 96, no. 2, pp. 524-531, 2003.

[204] K. Sato, T. Kimura, T. Nishikawa, Y. Tobe, and Y. Masaki, "Neuroprotective effects of a combination of dexmedetomidine and hypothermia after incomplete cerebral ischemia in rats," Acta Anaesthesiologica Scandinavica, vol. 54, no. 3, pp. 377-382, 2010.

[205] O. Eser, H. Fidan, O. Sahin et al., "The influence of dexmedetomidine on ischemic rat hippocampus," Brain Research, vol. 1218, pp. 250-256, 2008.

[206] J. Afonso and F. Reis, "Dexmedetomidine: current role in anesthesia and intensive care," Revista Brasileira de Anestesiologia, vol. 62, no. 1, pp. 118-133, 2012.

[207] S. Dahmani, A. Paris, V. Jannier et al., "Dexmedetomidine increases hippocampal phosphorylated extracellular signalregulated protein kinase 1 and 2 content by an $\alpha 2$-adrenoceptorindependent mechanism: evidence for the involvement of imidazoline I1 receptors," Anesthesiology, vol. 108, no. 3, pp. 457466, 2008.

[208] J. Shen, Y. Wu, J.-Y. Xu et al., "ERK- and Akt-dependent neuroprotection by erythropoietin (EPO) against glyoxal-AGEs via modulation of $\mathrm{Bcl}-\mathrm{xL}, \mathrm{Bax}$, and $\mathrm{BAD}$," Investigative Ophthalmology and Visual Science, vol. 51, no. 1, pp. 35-46, 2010.

[209] H. Kocoglu, K. Karaaslan, E. Gonca, O. Bozdogan, and N. Gulcu, "Preconditionin effects of dexmedetomidine on myocardial ischemia/reperfusion injury in rats," Current Therapeutic Research, vol. 69, no. 2, pp. 150-158, 2008.

[210] H. Kocoglu, H. Ozturk, H. Ozturk, F. Yilmaz, and N. Gulcu, "Effect of dexmedetomidine on ischemia-reperfusion injury in rat kidney: a histopathologic study," Renal Failure, vol. 31, no. 1, pp. 70-74, 2009.

[211] S. Dahmani, D. Rouelle, P. Gressens, and J. Mantz, "Effects of dexmedetomidine on hippocampal focal adhesion kinase tyrosine phosphorylation in physiologic and ischemic conditions," Anesthesiology, vol. 103, no. 5, pp. 969-977, 2005.

[212] R. C. Prielipp, M. H. Wall, J. R. Tobin et al., "Dexmedetomidineinduced sedation in volunteers decreases regional and global cerebral blood flow," Anesthesia and Analgesia, vol. 95, no. 4, pp. 1052-1059, 2002.

[213] M. H. Zornow, M. Maze, J. B. Dyck, and S. L. Shafer, "Dexmedetomidine decreases cerebral blood flow velocity in humans," Journal of Cerebral Blood Flow and Metabolism, vol. 13, no. 2, pp. 350-353, 1993.

[214] J. C. Drummond, A. V. Dao, D. M. Roth et al., "Effect of dexmedetomidine on cerebral blood flow velocity, cerebral metabolic rate, and carbon dioxide response in normal humans," Anesthesiology, vol. 108, no. 2, pp. 225-232, 2008.

[215] M. Schoeler, P. D. Loetscher, R. Rossaint et al., "Dexmedetomidine is neuroprotective in an in vitro model for traumatic brain injury," BMC Neurology, vol. 12, p. 20, 2012.

[216] D. S. Sulemanji, A. Dönmez, D. Aldemir, A. Sezgin, and S. Türkoglu, "Dexmedetomidine during coronary artery bypass 
grafting surgery: is it neuroprotective? - a preliminary study," Acta Anaesthesiologica Scandinavica, vol. 51, no. 8, pp. 10931098, 2007.

[217] M. T. Bell, F. Ferenc Puskas, P. D. Smith et al., "Attenuation of spinal cord ischemia-reperfusion injury by specific $\alpha$-2a receptor activation with dexmedetomidine," Journal of Vascular Surgery, vol. 56, pp. 1398-1402, 2012.

[218] J. Gu, P. Sun, H. Zhao et al., "Dexmedetomidine provides renoprotection against ischemia-reperfusion injury in mice," Critical Care, vol. 15, no. 3, article R153, 2011.

[219] B. Tufanogullari, P. F. White, M. P. Peixoto et al., "Dexmedetomidine infusion during laparoscopic bariatric surgery: the effect on recovery outcome variables," Anesthesia and Analgesia, vol. 106, no. 6, pp. 1741-1748, 2008.

[220] P. Jalowiecki, R. Rudner, M. Gonciarz, P. Kawecki, M. Petelenz, and P. Dziurdzik, "Sole use of dexmedetomidine has limited utility for conscious sedation during outpatient colonoscopy," Anesthesiology, vol. 103, no. 2, pp. 269-273, 2005.

[221] M. Muntazar and F. C. Kumar, "Cardiac arrest, a preventable yet a possible risk of dexmedetomidine: fact or fiction?" Anesthesiology, vol. 101, no. 6, pp. 1478-1480, 2004.

[222] A. N. Shah, J. Koneru, A. Nicoara, L. B. Goldfeder, K. Thomas, and F. A. Ehlert, "Dexmedetomidine related cardiac arrest in a patient with permanent pacemaker; a cautionary tale," Pacing and Clinical Electrophysiology, vol. 30, no. 9, pp. 1158-1160, 2007.

[223] D. L. Herr, S. T. J. Sum-Ping, and M. England, "ICU sedation after coronary artery bypass graft surgery: dexmedetomidinebased versus propofol-based sedation regimens," Journal of Cardiothoracic and Vascular Anesthesia, vol. 17, no. 5, pp. 576584, 2003.

[224] J. Jalonen, M. Hynynen, A. Kuitunen et al., "Dexmedetomidine as an anesthetic adjunct in coronary artery bypass grafting," Anesthesiology, vol. 86, no. 2, pp. 331-345, 1997.

[225] H. Karakaya Kabukçu, N. Sahin, Y. Temel, and T. Aydogdu Titiz, "Hemodynamics in coronary artery bypass surgery: effects of intraoperative dexmedetomidine administration," Anaesthesist, vol. 60 , no. 5, pp. 427-431, 2011.

[226] H. Guo, S. Takahashi, S. Cho, T. Hara, S. Tomiyasu, and K. Sumikawa, "The effects of dexmedetomidine on left ventricular function during hypoxia and reoxygenation in isolated rat hearts," Anesthesia and Analgesia, vol. 100, no. 3, pp. 629-635, 2005.

[227] H. Chen, H. Higashino, K. Maeda et al., "Reduction of cardiac norepinephrine improves postischemic heart function in stroke-prone spontaneously hypertensive rats," Journal of Cardiovascular Pharmacology, vol. 38, no. 6, pp. 821-832, 2001.

[228] P. M. Mertes, J. P. Carteaux, Y. Jaboin et al., "Estimation of myocardial interstitial norepinephrine release after brain death using cardiac microdialysis," Transplantation, vol. 57, no. 3, pp. 371-377, 1994.

[229] K. A. Bybee and A. Prasad, "Stress-related cardiomyopathy syndromes," Circulation, vol. 118, no. 4, pp. 397-409, 2008.

[230] V. C. Hachinski, K. E. Smith, and M. D. Silver, "Acute myocardial and plasma catecholamine changes in experimental stroke," Stroke, vol. 17, no. 3, pp. 387-390, 1986.

[231] V. H. Lee, J. K. Oh, S. L. Mulvagh, and E. F. M. Wijdicks, "Mechanisms in neurogenic stress cardiomyopathy after aneurysmal subarachnoid hemorrhage," Neurocritical Care, vol. 5, no. 3, pp. 243-249, 2006.
[232] H. M. Willigers, F. W. Prinzen, P. M. Roekaerts, S. de Lange, and M. E. Durieux, "Dexmedetomidine decreases perioperative myocardial lactate release in dogs," Anesthesia and Analgesia, vol. 96, no. 3, pp. 657-664, 2003.

[233] M. Karamazyn, R. E. Beamish, and N. S. Dhalla, "Involvement of calcium in coronary vasoconstriction due to prolonged hypoxia," American Heart Journal, vol. 107, no. 2, pp. 293-297, 1984.

[234] D. Pinsky, M. Oz, H. Liao et al., "Restoration of the cAMP second messenger pathway enhances cardiac preservation for transplantation in a heterotopic rat model," Journal of Clinical Investigation, vol. 92, no. 6, pp. 2994-3002, 1993.

[235] M. Kitakaze, M. Hori, K. Gotoh et al., "Beneficial effects of $\alpha 2$-adrenoceptor activity on ischemic myocardium during coronary hypoperfusion in dogs," Circulation Research, vol. 65, no. 6, pp. $1623-1645,1989$.

[236] M. F. Oliver, L. Goldman, D. G. Julian, and I. Holme, "Effect of mivazerol on perioperative cardiac complications during noncardiac surgery in patients with coronary heart disease: the European Mivazerol Trial (EMIT)," Anesthesiology, vol. 91, no. 4, pp. 951-961, 1999.

[237] D. N. Wijeysundera, J. S. Naik, and W. S. Beattie, "Alpha2 adrenergic agonists to prevent perioperative cardiovascular complications: a meta-analysis," American Journal of Medicine, vol. 114, no. 9, pp. 742-752, 2003.

[238] A. J. Rough, L. H. Kudo, and C. Hébert, "Dexmedetomidine inhibits osmotic water permeability in the rat cortical collecting duct," Journal of Pharmacology and Experimental Therapeutics, vol. 281, no. 1, pp. 62-69, 1997.

[239] F. T. Billings IV, S. W. C. Chen, M. Kim et al., “ $\alpha 2$-Adrenergic agonists protect against radiocontrast-induced nephropathy in mice," American Journal of Physiology-Renal Physiology, vol. 295, no. 3, pp. F741-F748, 2008.

[240] M. Taoda, Y. U. Adachi, Y. Uchihashi, K. Watanabe, T. Satoh, and E. S. Vizi, "Effect of dexmedetomidine on the release of [3H]noradrenaline from rat kidney cortex slices: characterization of $\alpha 2$-adrenoceptor," Neurochemistry International, vol. 38 , no. 4 , pp. 317-322, 2001.

[241] R. M. Venn, P. J. Newman, and R. M. Grounds, "A phase II study to evaluate the efficacy of dexmedetomidine for sedation in the medical intensive care unit," Intensive Care Medicine, vol. 29, no. 2, pp. 201-207, 2003.

[242] K. Reid, Y. Hayashi, T.-Z. Guo, C. Correa-Sales, C. NacifCoelho, and M. Maze, "Chronic administration of an $\alpha 2$ adrenergic agonist desensitizes rats to the anesthetic effects of dexmedetomidine," Pharmacology Biochemistry and Behavior, vol. 47, no. 1, pp. 171-175, 1994.

[243] A. G. Doufas, C.-M. Lin, M.-I. Suleman et al., "Dexmedetomidine and meperidine additively reduce the shivering threshold in humans," Stroke, vol. 34, no. 5, pp. 1218-1223, 2003.

[244] E. G. Elvan, B. Öç, Ş. Uzun, E. Karabulut, F. Coşkun, and Ü. Aypar, "Dexmedetomidine and postoperative shivering in patients undergoing elective abdominal hysterectomy," European Journal of Anaesthesiology, vol. 25, no. 5, pp. 357-364, 2008.

[245] G. A. Maccioli, "Dexmedetomidine to facilitate drug withdrawal," Anesthesiology, vol. 98, no. 2, pp. 575-577, 2003.

[246] A. S. Multz, "Prolonged dexmedetomidine infusion as an adjunct in treating sedation-induced withdrawal," Anesthesia and Analgesia, vol. 96, no. 4, pp. 1054-1055, 2003. 
[247] K. Baddigam, P. Russo, J. Russo, and J. D. Tobias, “Dexmedetomidine in the treatment of withdrawal syndromes in cardiothoracic surgery patients," Journal of Intensive Care Medicine, vol. 20, no. 2, pp. 118-123, 2005.

[248] A. Rovasalo, H. Tohmo, R. Aantaa, E. Kettunen, and R. Palojoki, "Dexmedetomidine as an adjuvant in the treatment of alcohol withdrawal delirium: a case report," General Hospital Psychiatry, vol. 28, no. 4, pp. 362-363, 2006.

[249] J. Darrouj, N. Puri, E. Prince, A. Lomonaco, A. Spevetz, and D. R. Gerber, "Dexmedetomidine infusion as adjunctive therapy to benzodiazepines for acute alcohol withdrawal," Annals of Pharmacotherapy, vol. 42, no. 11, pp. 1703-1705, 2008. 


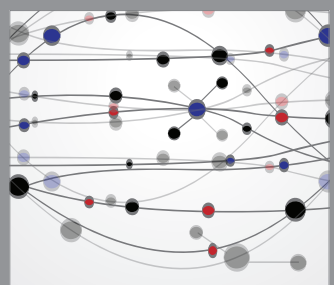

The Scientific World Journal
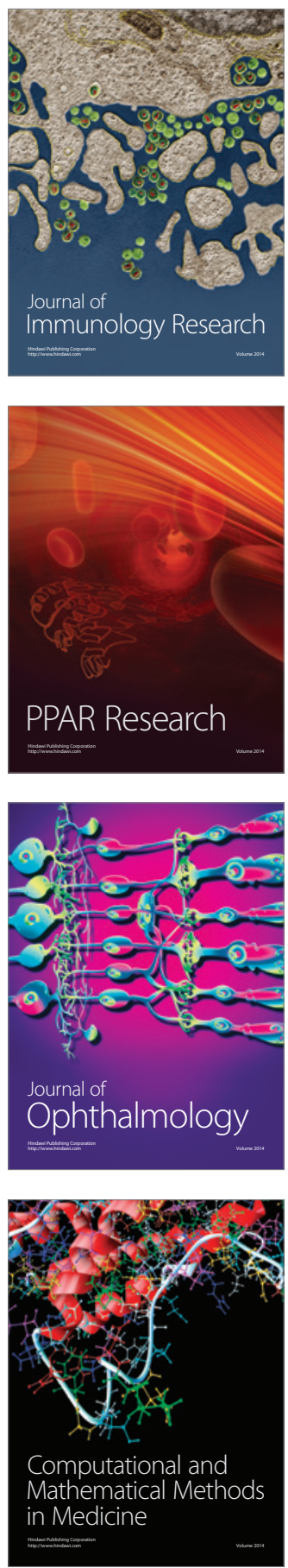

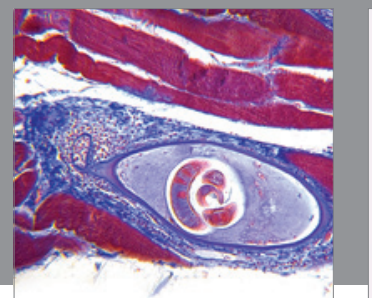

Gastroenterology

Research and Practice
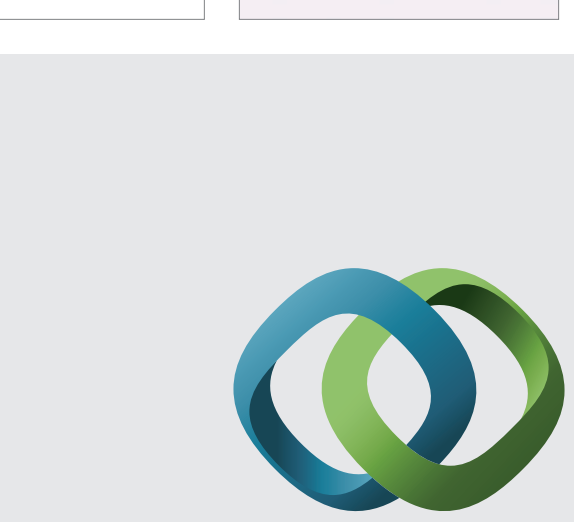

\section{Hindawi}

Submit your manuscripts at

http://www.hindawi.com
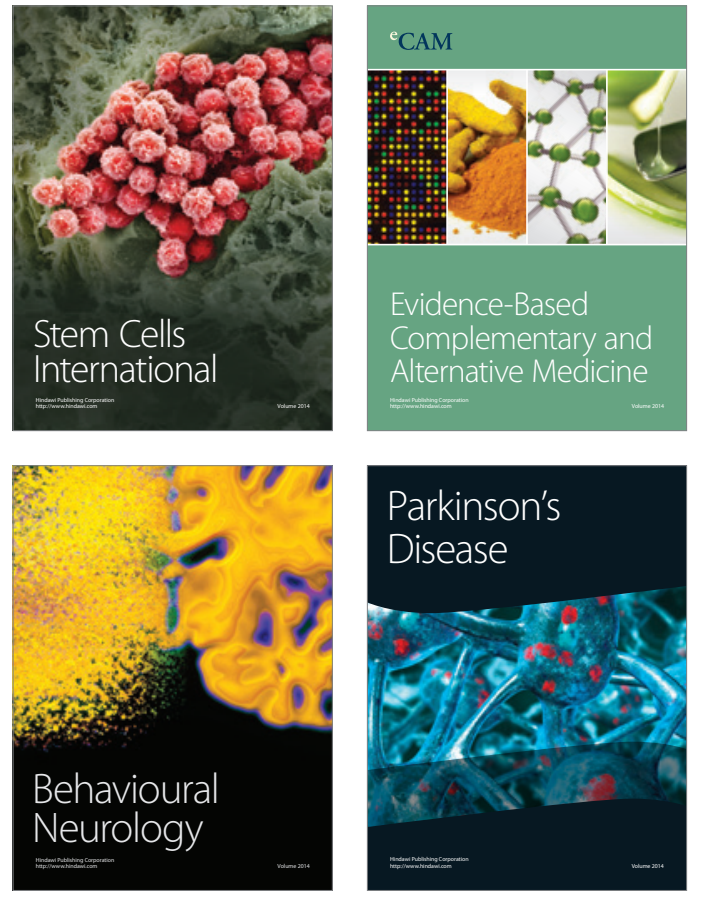
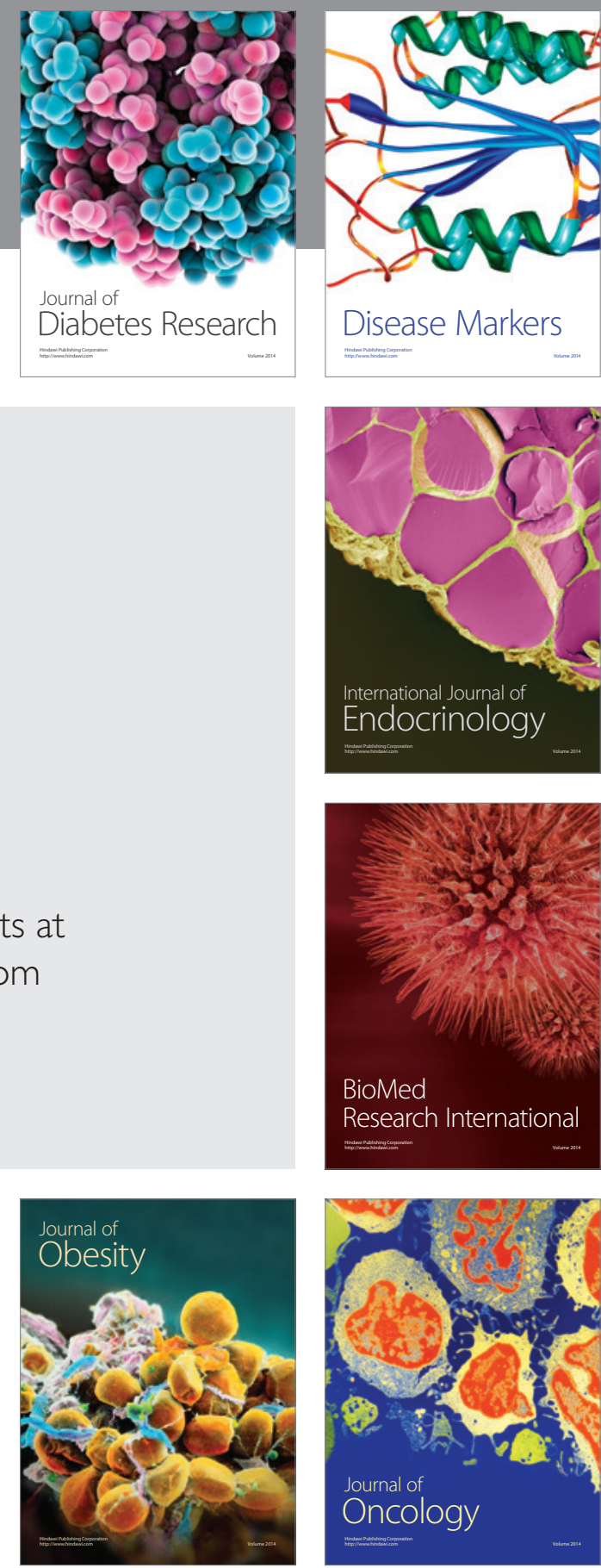

Disease Markers
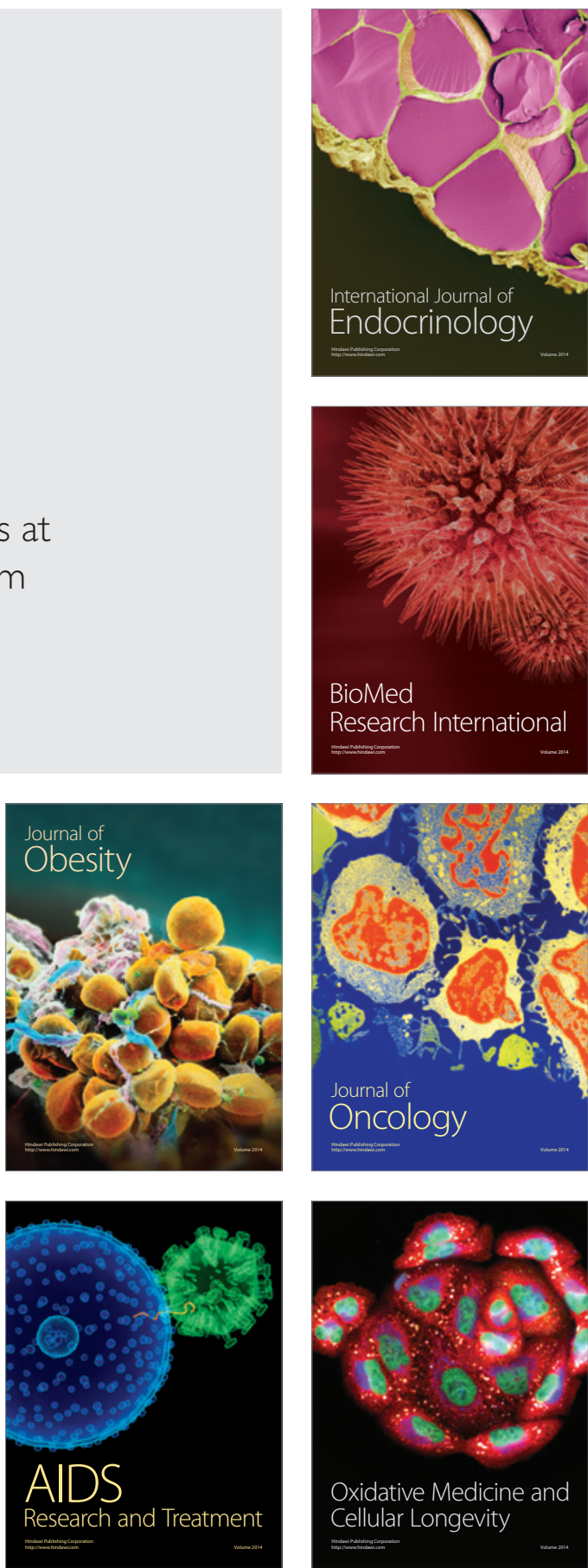